\title{
The Role of Adenosine Receptor A2A in the Regulation of Macrophage Exosomes and Vascular Endothelial Cells During Bone Healing
}

\author{
Dong Wang' \\ Jingyi Wang ${ }^{2}$ \\ Junlin Zhou $\mathbb{D}^{\prime}$ \\ Xi Zheng (D) ${ }^{2}$ \\ 'Department of Orthopedics, Beijing \\ Chaoyang Hospital, Capital Medical \\ University, Beijing, People's Republic of \\ China; ${ }^{2}$ Department of SICU, Beijing \\ Chaoyang Hospital, Capital Medical \\ University, Beijing, People's Republic of \\ China
}

Background: Macrophage exosomes and vascular endothelial cells (VECs) are critical to bone healing. However, few studies explore the molecular regulation of them in the bone fracture microenvironment.

Methods: In this study, we explored the effects of adenosine receptor A2A (ADA2AR) in macrophage exosomes and VECs during bone healing. CGS21680 (an ADA2AR agonist) and ZM241385 (an ADA2AR antagonist) were used. First, the effects of the ADA2AR on VECs during bone healing were studied in vivo in a rat tibial fracture model. Second, the effects of ADA2AR on VECs and in the regulation of VECs by macrophages were examined in the bone fracture microenvironment. Third, the effects of ADA2AR on the regulation of macrophage exosomes on VECs were analyzed. Finally, the genes and long non-coding RNAs (IncRNAs) associated with the regulation of VECs by the ADA2AR were examined by high-throughput sequencing and bioinformatics analysis.

Results: CGS21680 accelerated VEC proliferation in the early stage of bone healing and that ZM241385 suppressed VEC proliferation in vivo. ZM241385 inhibited cell viability and tube formation in vitro. However, CGS21680 did not promote tube formation, cell proliferation, or cell migration in vitro. The inhibition of macrophage exosomes could suppress tube formation and VEC migration. CGS21680 had no effects on tube formation in a macrophageVEC co-culture. The macrophage exosomes were purified and CGS21680 promoted the macrophage secretion of exosomes. In contrast, ZM241385 inhibited the macrophage secretion exosomes. Finally, the lncRNA and mRNA involved in the activation of the ADA2AR in VECs were analyzed. CGS21680 upregulated 3274 mRNAs and downregulated 2236 mRNAs, and upregulated 1696 lncRNAs and downregulated 1882 lncRNAs. The hub genes involved in angiogenesis were Flt1, Fgf2, Mapk14, Fn1, and Jun.

Conclusion: The activation of ADA2AR was essential for angiogenesis and the secretion of exosomes by macrophages during bone healing; moreover, the inactivation of the ADA2AR led to poor angiogenesis and bone nonunion.

Keywords: adenosine A2A receptor, angiogenesis, vascular endothelial cells, macrophages, bone healing

\section{Introduction}

Bone fracture is a common cause of disability and the nonunion rate is approximately 5$10 \%$ despite patients receiving active treatment. ${ }^{1-3}$ Poor vascularization leads to nonunion, and vascular endothelial cells (VECs) are known to be critical to nonunion. ${ }^{3-6}$ Damaged VECs release many bioactive factors, which accelerate VEC proliferation and
Correspondence: Xi Zheng Department of SICU, Beijing Chaoyang Hospital, Capital Medical University, Beijing, People's Republic of China Email xizheng_article@outlook.com 
migration during the initial process of angiogenesis after bone fracture. ${ }^{7-9}$ If VECs become dysfunctional or their activation is suppressed, angiogenesis is blocked. ${ }^{7-9}$

Macrophages act as an activator for the secretion of a variety of growth factors, similar to damaged VECs in the early stage of bone healing. ${ }^{10-12}$ However, few studies have examined the molecular regulation of VECs in the bone fracture microenvironment.

The adenosine A2A receptor (ADA2AR), a member of the G-protein coupled receptor family, is an immunosuppressive and anti-inflammatory molecule. ${ }^{2,13,14}$ There have been no studies on the role of the ADA2AR in angiogenesis during bone healing and the effects of ADA2AR on VECs are still under debate. ${ }^{15-23}$ Desai et al ${ }^{20-22}$ proposed that ADA2AR agonists could promote vascular tube formation in vitro, but some studies found that adenosine $\mathrm{A} 1$ or $\mathrm{A} 2 \mathrm{~B}$ receptor agonists were the receptor subtypes of adenosine that promoted VEC proliferation or angiogenesis. ${ }^{21,22}$ CGS21680 (an ADA2AR agonist) did not mimic the stimulatory effects of adenosine on VECs. ${ }^{21,22}$ Ernens et $\mathrm{al}^{24}$ found that adenosine increased macrophage production of thrombospondin-1 (TSP-1) via the ADA2AR and the adenosine A2B receptor to stimulate angiogenesis in myocardial infarction. Du et $\mathrm{al}^{25}$ proposed that N-ethylcarboxamidoadenosine (NECA), a non-selective adenosine receptor agonist, increased tube formation in human microvascular endothelial cells via the adenosine A2B receptor by upregulating VEGF and eNOS. In 2020, we proposed that CGS21680 could promote fracture healing. ${ }^{2}$ However, the role of the ADA2AR in angiogenesis and its effects on VECs in the bone fracture microenvironment have not been discussed.

In this study, we explored the effect of the ADA2AR in macrophage exosomes and VECs during bone healing. CGS21680 and ZM241385 (an ADA2AR antagonist) were used. First, the effect of the ADA2AR on VECs during bone healing was studied in vivo in a rat tibial fracture model. Second, we examined the effects of the ADA2AR on VECs in the bone fracture microenvironment and in the regulation of VECs by macrophages using a cell co-culture model. Third, we analyzed the effects of the ADA2AR on the regulation of macrophage exosomes on VECs in vitro. Finally, the genes and long non-coding RNAs (lncRNAs) associated with the regulation of VECs by the ADA2AR were examined by high-throughput sequencing and bioinformatics analysis.

\section{Materials and Methods}

\section{Animals}

Female adult Sprague-Dawley (SD) rats (Charles River Laboratories, body weight $200 \pm 20$ g) were used and kept in separate sterile cages. The feeding environment was specific pathogen free. The rats were maintained under a $12 \mathrm{~h}$ light/ dark cycle at $23.6^{\circ} \mathrm{C}$ and $35 \%$ humidity with free access to sterilized chow diet and water. All procedures complied with the ARRIVE guidelines and the National Institutes of Health Guidelines for the Care and Use of Laboratory Animals. This study was approved by the Capital Medical University Ethics Committee.

The following humane endpoints were applied: extreme difficulty in moving to get food or water; severe wound infection; limb necrosis; autophagia; and screaming in response to a gentle touch. At the end of the experiment or when humane endpoints were reached, the rats were euthanized by an excessive dose of sodium pentobarbital (100 mg/ $\mathrm{kg}$, intraperitoneal injection). Animal death was confirmed by the absence of breathing or heartbeat. All the drug concentrations used were physiologically appropriate.

\section{Animal Sample Size}

Stata/SE 12.0 (StataCorp LP, USA) software was used to calculate the required animal sample size. For the in vivo experiments, the tibia fracture nonunion model was used and the sample size was estimated by referring to previous studies on the ADA2AR promotion of fracture healing, because there have been no studies of how the ADA2AR accelerates angiogenesis in bone healing. ${ }^{2,26}$ The study showed that the ADA2AR promoted bone healing (the rate of increase was $100 \%$ ) and the fracture healing rate of the control group was 0 at 8 weeks. ${ }^{2,26}$ In addition, $\alpha$ was set as 0.05 (two-sided), the failure rate of the model was $10 \%$, and $1-\beta$ was set as 0.80 . Therefore, at least five rats were needed for each time point. In the in vitro experiments, 12 rats were used to extract the macrophages from the peripheral blood and eight rats were used to prepare the bone fracture environment.

\section{Cells and Reagents}

Rat VECs were purchased from Procell company (CP-R075, Procell, China) and authenticated by Procell company via CD31 immunofluorescence assay in Supplementary Material. Complete culture medium for rat aortic endothelial cells (CM-R075, Procell) was used to culture the VECs. All the reagents used in this study are presented in 
Supplementary Material. Cells were not pre-incubated with CGS21680 and ZM241385 in all the experiments.

\section{Extraction of Macrophages from the Peripheral Blood}

The method for macrophage extraction the from peripheral blood was similar to that used in previous studies. ${ }^{2,27,28}$ Briefly, the peripheral blood of rats was collected in an anticoagulant tube and volume diluted 1:1 by DPBS. Then, the diluted blood was slowly layered onto the rat lymphocyte separation medium, and then centrifuged at $1800 \mathrm{rpm}$ for 20 min. The peripheral blood mononuclear cell (PBMC) layers were harvested and resuspended in RPMI-1640 with $10 \%$ FBS. After incubation for $2 \mathrm{~h}$, the adherent cells were harvested.

The cells were resuspended in DPBS and incubated with rabbit anti-CD68/Alexa Fluor 488 antibody (1:100 dilution) or with rabbit IgG/Alexa Fluor 488 (1:100 dilution, isotype control) in the dark at $4{ }^{\circ} \mathrm{C}$ for $30 \mathrm{~min}$. Flow cytometry (FCM) was used to detect the ratio of positively stained cells.

\section{Construction of Bone Fracture Environment Medium}

The tibia fracture model was established in eight SD rats in a similar manner to previous studies; ${ }^{2}$ see also Supplementary Material. After 7 days, the peripheral blood was collected and centrifuged at $2500 \mathrm{rpm}$ for $25 \mathrm{~min}$. The rat serum was harvested and heated at $56^{\circ} \mathrm{C}$ for $30 \mathrm{~min}$ to inactivate the complement. Then, 5\% serum and 95\% low-sugar Dulbecco's modified eagle medium (L-DMEM, GD3104500ML, Genview, China) was used as the bone fracture medium (BFM).

\section{Evaluation of the Effect of the ADA2AR on VECs During Bone Healing}

The rat tibia fracture model was used to evaluate the effect of the ADA2AR on VECs during bone healing. First, $10 \mathrm{mg}$ CGS21680 or ZM241385 was dissolved in $50 \mu \mathrm{L}$ DMSO by shaking in an ultrasonic bath for 2 min and 1:100 diluted in normal saline.

Forty-five rats were divided into three groups: CGS21680 treatment, ZM241385 treatment, and DMSO treatment (control). The rats were administered $100 \mu \mathrm{L}$ of diluted CGS21680, ZM241385, or DMSO using a sterile sponge as the drug carrier, which was placed around the fracture end. Subsequently, $100 \mu \mathrm{L}$ of diluted CGS21680,
ZM241385, or DMSO was administered as a bone fracture site injection every $24 \mathrm{~h}$ according until an endpoint was reached (Figure 1A). At each time point, (7, 14, and 28 days after modeling), five rats from each group were randomly selected for analysis and euthanized.

Bone tissue HE staining, von Willebrand factor (vWF) immunohistochemical staining, CD31 immunofluorescence staining, and Goldner trichrome staining were used to evaluate the effect of ADA2AR on VECs during bone healing. Details of the analysis methods are presented in Supplementary Material.

\section{Evaluation of the Effect of the ADA2AR on VECs in the Bone Fracture}

\section{Environment}

The CCK-8 assay, EdU/PI staining, cell migration assay, vascular tube formation assay, and cell scratch assay were used to evaluate the effects of the ADA2AR on VECs in the bone fracture microenvironment. Each experiment was repeated five times.

\section{CCK-8 Assay}

VECs (2000 cells/well) were seeded in a 96-well plate and incubated overnight; then, BFM was added (200 $\mu \mathrm{L} /$ well). The cells were divided into four treatment groups: $100 \mathrm{ng} /$ $\mu \mathrm{L}$ CGS21680, $100 \mathrm{ng} / \mu \mathrm{L}$ ZM241385, $0.2 \mu \mathrm{L}$ DPBS, and $0.2 \mu \mathrm{L}$ DMSO. After incubation for $48 \mathrm{~h}, 20 \mu \mathrm{L}$ of CCK-8 reagent was added into each well, and the cells were incubated for $2 \mathrm{~h}$. The cell viability was proportional to the absorbance of each well at $450 \mathrm{~nm}$, as measured using a microplate reader. (The results of different concentrations CGS21680 and ZM241385 on VECs are presented in Supplementary Material).

\section{EdU/PI Staining}

EdU/PI staining was performed as described previously. ${ }^{29}$ Briefly, VECs $\left(10^{7}\right.$ cells) were seeded in a 6-well plate and incubated overnight. Then, BFM was added $(2.5 \mathrm{~mL} /$ well $)$ and the cells were divided into three treatment groups: 100 $\mathrm{ng} / \mu \mathrm{L}$ CGS 21680, $100 \mathrm{ng} / \mu \mathrm{L}$ ZM241385, and $1.25 \mu \mathrm{L}$ DMSO. The treatments were applied for $48 \mathrm{~h}$. The celllight EdU Apollo 488 in vitro flow cytometry kit (C103383 , Ribobio) and propidium iodide (PI) were used to detect the cells. The kits were used in accordance with the manufacturer's instructions. 
A
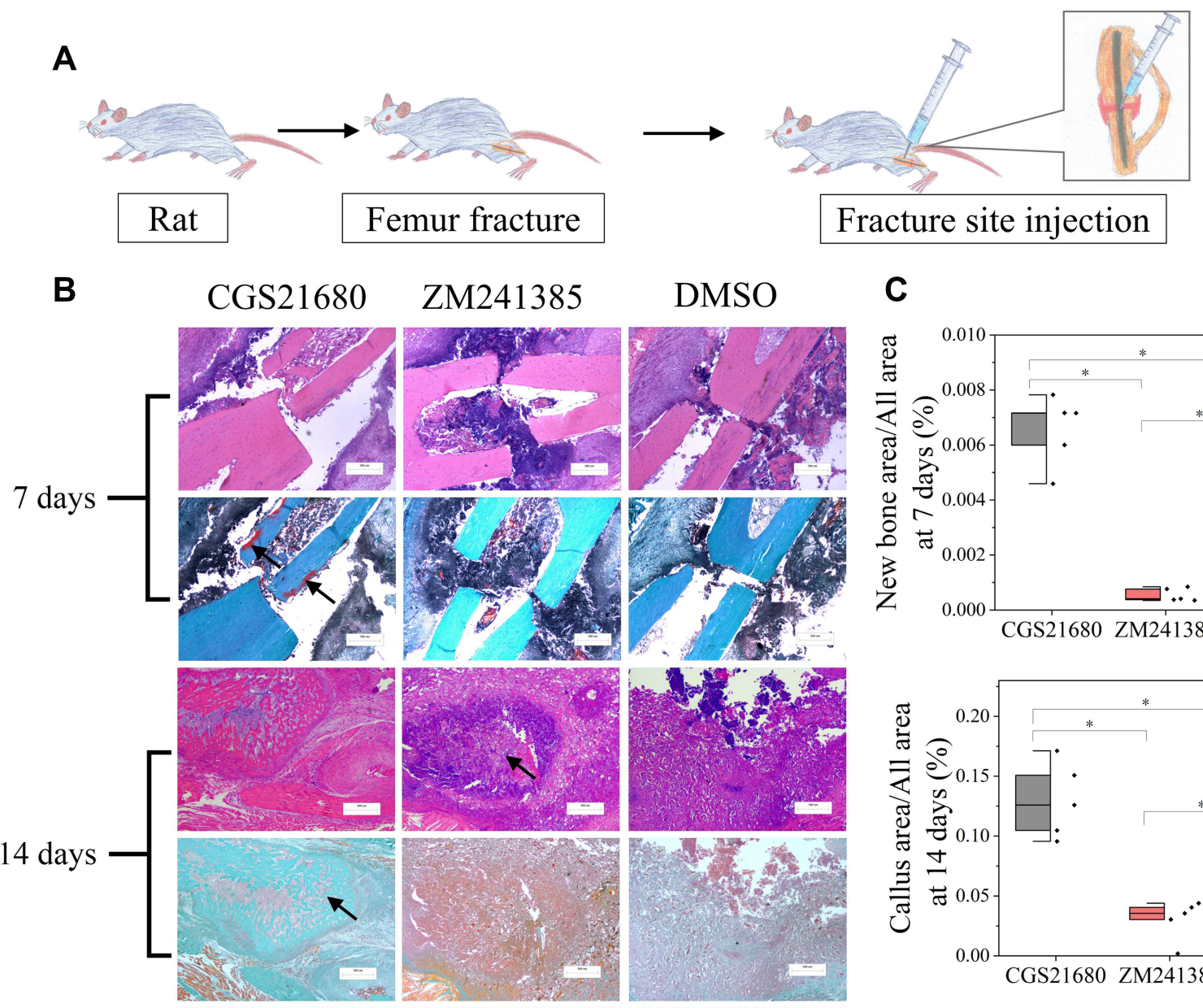

DMSO
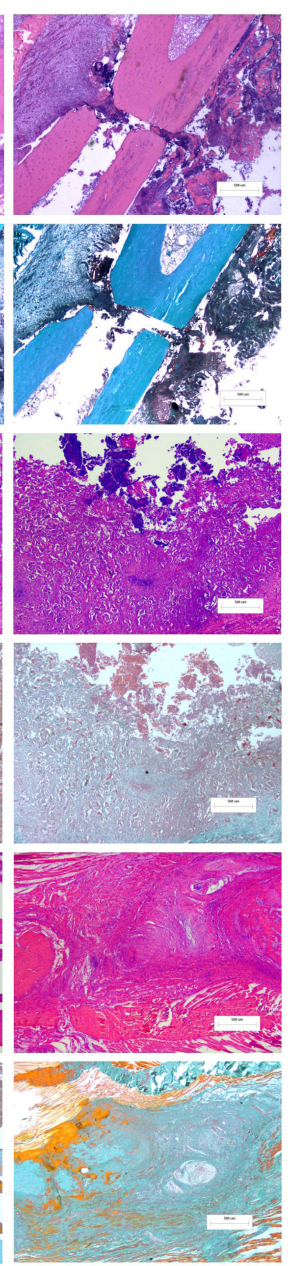

C
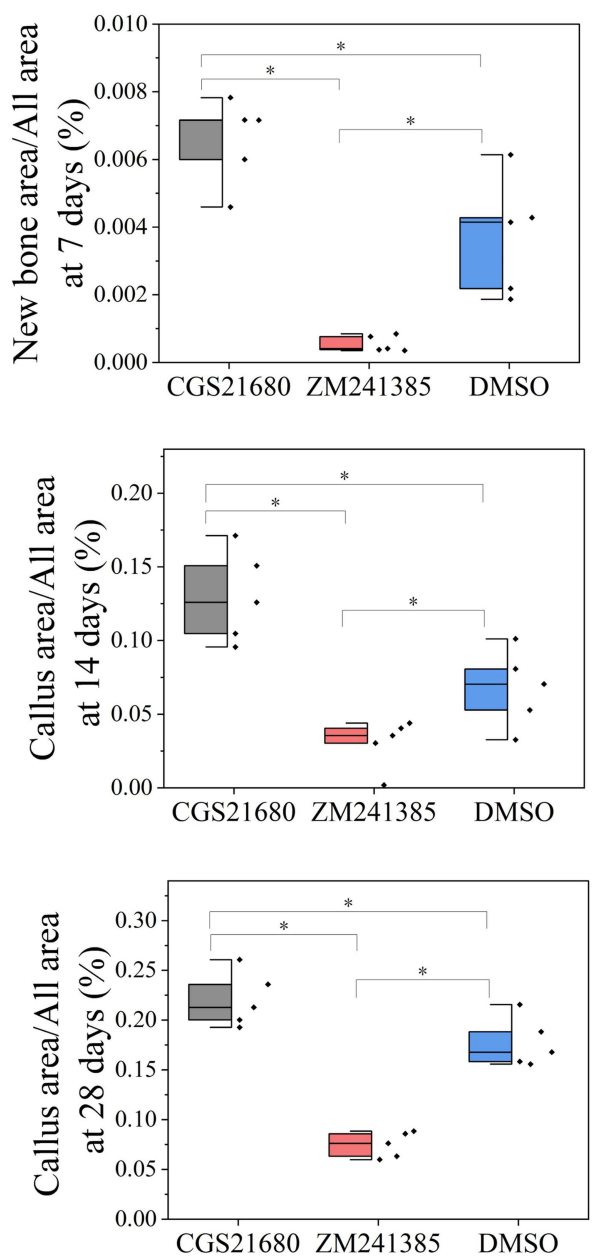

Figure I The role of ADA2AR on bone healing. (A) A schematic diagram. 45 rats were divided into 3 groups and were received fracture site injection after modeling. (B) $\mathrm{HE}$ staining and Goldner trichrome staining of the fracture site. CGS21680 promoted the new bone formation at 7 days (red region, arrows) and callus formation at 14,28 days (arrows), while ZM24I385 inhibited bone formation and caused serious inflammatory reaction at 14, 28 days (arrows). Images, $\times 25$; original scale bar, $500 \mu \mathrm{m}$. (C) halfbox graphs showed the difference between groups, ${ }^{*} p<0.05$. $n=5$ at each timepoint.

\section{Cell Migration Assay}

Transwell inserts (pore size: $8 \mu \mathrm{m}$ ) were used. The concentration of VECs was adjusted to 250 cells $/ \mu \mathrm{L}$ and 200 $\mu \mathrm{L}$ of the cell suspension was plated in the top chamber. The lower chamber contained $600 \mu \mathrm{L}$ BFM. The cells were divided into five treatment groups: $100 \mathrm{ng} / \mu \mathrm{L}$ CGS21680, 100 ng/ $\mu \mathrm{L}$ ZM241385, $0.8 \mu \mathrm{L}$ DMSO, positive control (complete medium in the lower chamber), and negative control (BFM). The cells were incubated for 48 $\mathrm{h}$ and migration was observed; ${ }^{30}$ details of the analysis methods are presented in Supplementary Material.

\section{Tube Formation Assay}

The vascular tube formation assay used was similar to that described in a previous study. ${ }^{31}$ Briefly, $400 \mu \mathrm{L}$ of melted Matrigel was added to each well (12-well plate) and solidified at $37^{\circ} \mathrm{C}$ for $30 \mathrm{~min}$. The VECs $\left(2 \times 10^{5}\right.$ cells/well $)$ were incubated on the Matrigel-coated plate with $1.6 \mathrm{~mL} /$ 
well BFM. The cells were divided into three treatment groups: $100 \mathrm{ng} / \mu \mathrm{L}$ CGS21680, $100 \mathrm{ng} / \mu \mathrm{L} \mathrm{ZM} 241385$, and $1.6 \mu \mathrm{L}$ DMSO. After incubation for $12 \mathrm{~h}$, the cells were observed under a microscope, and then incubated with a $1: 20$ diluted in Calcein-AM at $37^{\circ} \mathrm{C}$ for $30 \mathrm{~min}$. Then, the fluorescence was observed with a fluorescence inverted microscope. Details of the analysis method are presented in Supplementary Material.

\section{Scratch Assay}

Briefly, VECs were incubated in a 6-well plate with $2.5 \mathrm{~mL} /$ well BFM and divided into three treatment groups: $100 \mathrm{ng} / \mu \mathrm{L}$ CGS21680, $100 \mathrm{ng} / \mu \mathrm{L}$ ZM 241385, and $2.5 \mu \mathrm{L}$ DMSO. A $100-\mu \mathrm{L}$ pipette tip was used to make a scratch in the surface of the cells and the wound area was observed under a microscope at $0 \mathrm{~h}, 24 \mathrm{~h}$, and $48 \mathrm{~h}$ after scratching. Details of the analysis methods are presented in Supplementary Material.

\section{Evaluation of the Effect of the ADA2AR on Macrophage Regulation of VECs in vitro}

The cell migration assay and vascular tube formation assay in the cell co-culture model were used to evaluate the effects of the ADA2AR on the macrophage regulation of VECs in vitro. Each experiment was repeated five times.

\section{Cell Migration Assay}

Transwell inserts (pore size, $8 \mu \mathrm{m}$ ) were used. Macrophages $\left(10^{5}\right.$ cells/well) were incubated in the lower chamber with $600 \mu \mathrm{L} \mathrm{BFM}$ and VECs $\left(5 \times 10^{4}\right.$ cells/well $)$ were incubated in the upper chamber with $200 \mu \mathrm{L}$ BFM. Six treatments were applied: $100 \mathrm{ng} / \mu \mathrm{L}$ CGS21680, $100 \mathrm{ng} / \mu \mathrm{L}$ ZM241385, 6.58 $\mu \mathrm{L}$ DMSO, $100 \mathrm{ng} / \mu \mathrm{L}$ CGS21680+10 $\mu \mathrm{M}$ GW4869, positive control (complete medium in the lower chamber), and negative control (BFM). After incubation for $48 \mathrm{~h}$, the cell migration was observed. Detailed analysis methods are presented in Supplementary Material.

\section{Tube Formation Assay}

A vascular tube formation assay was performed in the cell co-culture model. Briefly, Transwell inserts (pore size, 0.4 $\mu \mathrm{m}$ ) were used and the lower chamber was coated with $200 \mu \mathrm{L}$ of Matrigel. The macrophages were incubated in the upper chamber and the VECs were incubated in the lower chamber. Four treatments were applied: $100 \mathrm{ng} / \mu \mathrm{L}$ CGS21680, $100 \mathrm{ng} / \mu \mathrm{L}$ ZM241385, $6.58 \mu \mathrm{L}$ DMSO, 100 $\mathrm{ng} / \mu \mathrm{L}$ CGS21680+10 $\mu \mathrm{M}$ GW4869. After incubation for $12 \mathrm{~h}$, the extent of vascular tube formation was observed. Details of the analysis methods are presented in Supplementary Material.

\section{Evaluation of the Effect of the ADA2AR on Macrophages Exosomes Regulation of VECs in vitro}

Cell fluorescence tracing, cell migration assay, and the vascular tube formation assay were used to evaluate the effect of the ADA2AR on the regulation of VECs by macrophage exosomes. Each experiment was repeated five times. Macrophage exosomes were purified by ultracentrifugation. The extraction methods and authentication of exosomes are presented in Supplementary Material.

\section{Cell Fluorescence Tracing Assay}

Transwell inserts (pore size, $0.4 \mu \mathrm{m}$ ) were used. Macrophages were stained with DiD (D4019, Yuheng) and VECs werestained by $\mathrm{DiO}$ (D4007, Yuheng). The marking process was performed in accordance with the manufacturer's instructions. Then, the cell co-culture model was constructed. Macrophages $\left(10^{5}\right.$ cells/well $)$ were incubated in the lower chamber with $600 \mu \mathrm{L}$ BFM and VECs $\left(5 \times 10^{4}\right.$ cells/well) were incubated in the upper chamber with $200 \mu \mathrm{L}$ BFM. Four treatments were applied: $100 \mathrm{ng} / \mu \mathrm{L}$ CGS21680, $100 \mathrm{ng} / \mu \mathrm{L}$ ZM241385, $6.58 \mu \mathrm{L}$ DMSO, and $100 \mathrm{ng} / \mu \mathrm{L}$ CGS21680+10 $\mu \mathrm{M}$ GW4869. After incubation for $48 \mathrm{~h}$, the upper chamber was observed with a fluorescence inverted microscope.

\section{Cell Migration Assay}

Briefly, macrophages $\left(10^{5}\right.$ cells/well $)$ were incubated in a 24-well plate with $600 \mu \mathrm{L}$ BFM. Four treatments were applied: $100 \mathrm{ng} / \mu \mathrm{L}$ CGS21680 and $100 \mathrm{ng} / \mu \mathrm{L}$ CGS21680 $+10 \mu \mathrm{M}$ GW4869, positive control (complete medium), and negative control (BFM). After incubation for $48 \mathrm{~h}$, the cell suspension was harvested and added to the lower chamber with a Transwell insert (pore size, $8 \mu \mathrm{m}$ ). VECs $\left(5 \times 10^{4}\right.$ cells/well) were incubated in the upper chamber with $200 \mu \mathrm{L}$ BFM. After incubation for $48 \mathrm{~h}$, the migration of VECs was observed. Details of the analysis methods are presented in Supplementary Material.

\section{Tube Formation Assay}

Briefly, macrophages $\left(2 \times 10^{5}\right.$ cells/well $)$ were incubated in a 12-well plate with $1.6 \mathrm{~mL}$ BFM. The cells were divided 
into four treatment groups: $100 \mathrm{ng} / \mu \mathrm{L}$ CGS21680, $100 \mathrm{ng} /$ $\mu \mathrm{L} \quad \mathrm{ZM} 241385,13.16 \mu \mathrm{L}$ DMSO, and $100 \mathrm{ng} / \mu \mathrm{L}$ CGS21680+10 $\mu \mathrm{M}$ GW4869. After incubation for $48 \mathrm{~h}$, the cell suspension was harvested. VECs were resuspended in the harvested cells and added to a Matrigelcoated 12-well plate $\left(10^{5}\right.$ cells/well). After incubation for $12 \mathrm{~h}$, vascular tube formation was observed. Details of the analysis methods are presented in Supplementary Material.

\section{Evaluation of the IncRNAs and mRNAs Involved in the Regulatory Effect of the ADA2AR on VECs}

High-throughput sequencing was used to determine the lncRNAs and mRNAs involved in VEC regulation. The methods were similar to those in previous study. ${ }^{32}$ VECs were divided into two treatment groups: $100 \mathrm{ng} / \mu \mathrm{L}$ CGS21680 and DMSO. After incubation for $48 \mathrm{~h}$ with $5 \mathrm{~mL}$ BFM, the cells were harvested and transferred to Beijing Novogene Technology Co., Ltd., who performed high-throughput sequencing and analysis.

DAVID Bioinformatics Resources 6.8 was used to perform Gene Ontology (GO) and Kyoto Encyclopedia of Genes and Genomes (KEGG) analyses. ${ }^{33,34}$ P-values of less than 0.05 and gene enrichment of greater than 2-fold were the criteria for both analyses. WebGestalt, a web-based gene set analysis toolkit, was used to perform the gene set enrichment analysis (GSEA). ${ }^{35}$ The minimum number of IDs in the category was 3 and the maximum number of IDs in the category was 10,000 . The significance level was FDR $<0.1$ and the number of permutations was 1000 . The STRING 11.0 database was used to construct the protein-protein interaction (PPI) networks. ${ }^{36}$ The confidence score for selection was greater than or equal to 0.4 . The hub genes in the PPI networks were determined according to the degree centrality and the betweenness centrality, as calculated by Cytoscape 3.8.0 software. $^{37,38}$

\section{Statistical Analysis}

Stata/SE 12.0 software was used to analyze the data. The Shapiro-Wilk test was used to evaluate the normality of the data. If the measured data were normally distributed, it was described as the mean \pm standard deviation; comparisons between two groups were performed by an independentsample $t$-test, and comparisons between more than two groups were performed by one-way ANOVA; and least significant difference (LSD) tests were used for post hoc analysis. If the measurement data followed a skewed distribution, it was described by the median (interquartile range); comparisons between two groups were performed by the MannWhitney $U$-test, and comparisons between more than two groups were performed using the Kruskal-Wallis $H$-test. The enumeration data were represented by occurrence rate and compared by Chi-square test or Fischer's exact test. A P value of $<0.05$ was considered to indicate a statistically significant difference.

Full details of the image analysis methods are presented in the Supplementary Material.

\section{Results}

\section{Effect of the ADA2AR on VECs During Bone Healing}

CGS21680 significantly increased new bone formation and callus formation $(\mathrm{p}<0.05)$ (Figure 1B-D). However, ZM241385 increased necrotic tissue and delayed bone healing. With ZM241385 treatment, after 28 days, there was a lot of inflammatory necrotic tissue between the fracture ends and little new bone formation had occurred, whereas many calluses were formed in rats treated with CGS21680 (Figure 1B).

CGS21680 increased the vWF- and CD31-positive areas at 7 and 14 days; these increases were statistically significant $(\mathrm{p}<0.05) \quad$ (Figure $2 \mathrm{~A}-\mathrm{C})$, indicating that CGS21680 increased the number of VECs in the fracture site. There was little positive staining in the rats treated with ZM241385, indicating that ZM241385 inhibited the proliferation of VECs and angiogenesis in the fracture site (Figure 2A).

\section{Effect of the ADA2AR on VECs in the Bone Fracture Environment}

The cell migration results showed that neither CGS21680 nor ZM241385 increased the number of migrating cells compared with DMSO treatment, with no statistically significant changes observed $(p=0.133$ and $p=0.387$, respectively) (Figure 3C and D).

The CCK-8 assay showed that cells treated with ZM241385 had the lowest viability, and that this decrease was statistically significant $(\mathrm{p}<0.01)$ (Figure 4A). CGS21680 (100 ng/ $\mu \mathrm{L}, 50 \mathrm{ng} / \mu \mathrm{L}, 25 \mathrm{ng} / \mu \mathrm{L}, 10 \mathrm{ng} / \mu \mathrm{L}, 5$ $\mathrm{ng} / \mu \mathrm{L}, 2.5 \mathrm{ng} / \mu \mathrm{L}, 1 \mathrm{ng} / \mu \mathrm{L}, 0.5 \mathrm{ng} / \mu \mathrm{L}, 0.25 \mathrm{ng} / \mu \mathrm{L}$, and $0.05 \mathrm{ng} / \mu \mathrm{L}$ ) did not increase viability compared with treatment with DMSO or DPBS ( $p>0.05$ ). The effects of different concentrations of CGS21680 on VEC viability are presented in Supplementary Material. 


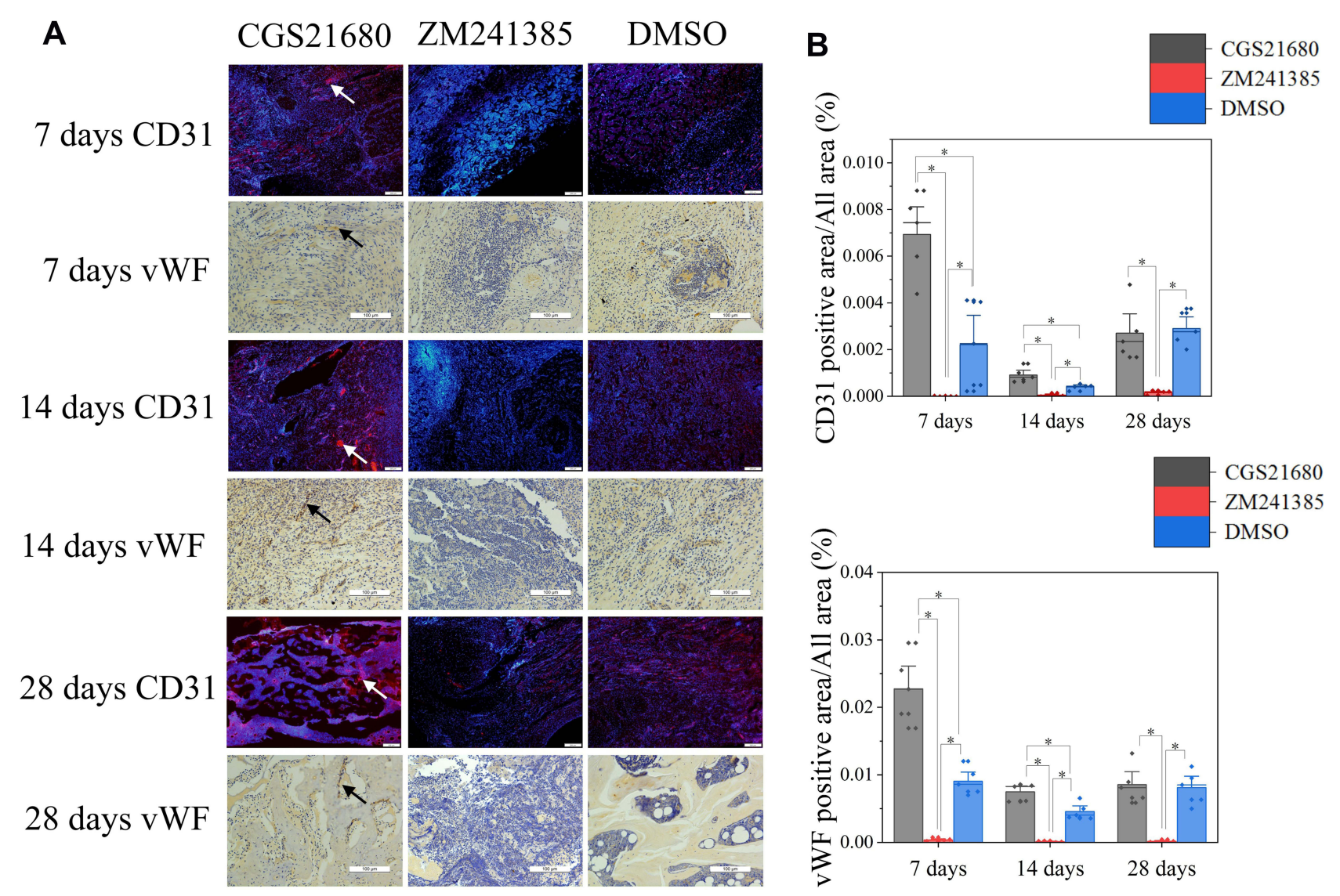

Figure 2 The role of ADA2AR on VECs during bone healing. (A) CD3I immunofluorescent staining and vWF immunohistochemical staining. CGS2 I680 promoted CD3। (red, arrows) and vWF (brown, arrows) expression at 7, 14, 28 days. Immunofluorescent images, $\times 40$; original scale bar, $200 \mu \mathrm{m}$. Immumohistochemical images, $\times 200$; original scale bar, $100 \mu \mathrm{m}$. (B) Bar graphs showed the difference between groups, ${ }^{*} \mathrm{p}<0.05$. $\mathrm{n}=5$ at each timepoint.

A

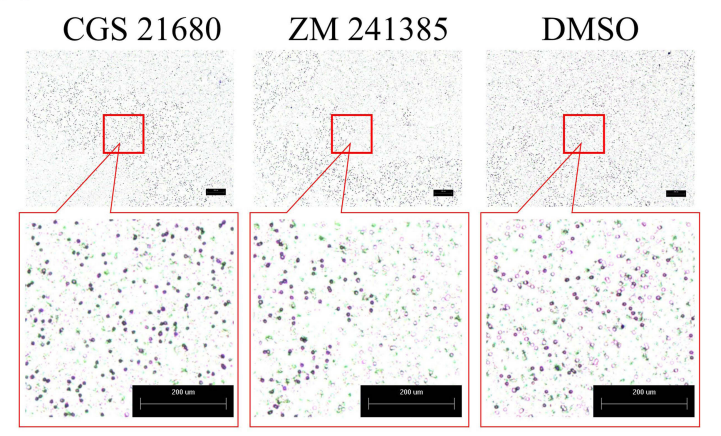

B

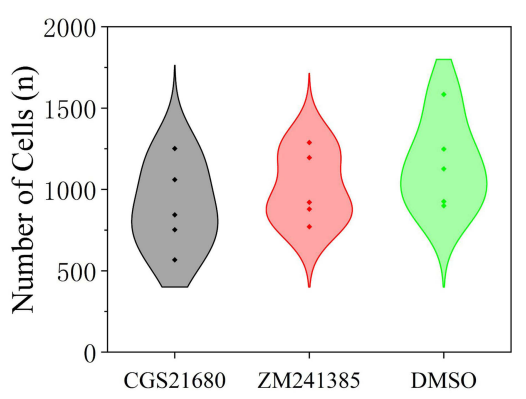

Figure 3 The role of ADA2AR on VECs migration in bone fracture environment in vitro. (A) CGS2I680 and ZM24I385 could not promote cell migration at $48 \mathrm{~h}$. (B) The violin plots showed the the difference between groups, ${ }^{*} \mathrm{p}<0.05$. Transwell images, $\times 50$; original scale bar, $200 \mu \mathrm{m}$. $\mathrm{n}=5 \mathrm{for}$ each group.

EdU (FITC)/PI staining showed that CGS21680 did not significantly increase the proportion of FITC-stained cells compared with DMSO treatment $(\mathrm{p}=0.249)$ but decrease the proportion of PI-stained cells ( $\mathrm{p}=0.038$ ), whereas cells treated with ZM241385 had lower FITC- and PI-stained cells than the other groups (Figure 4B and C). The results of the EdU with PI assay showed that CGS21680 did not accelerate the proliferation of VECs proliferation and that ZM241385 treatment inhibited VEC proliferation.

The results of the cell scratch assay showed that ZM241385 treatment inhibited the wound closure compared with CGS21680 or DMSO treatment, and that this difference was statistically significant $(p<0.01)$ (Figure 4D and E). However, CGS21680 treatment did not enhance the 
A

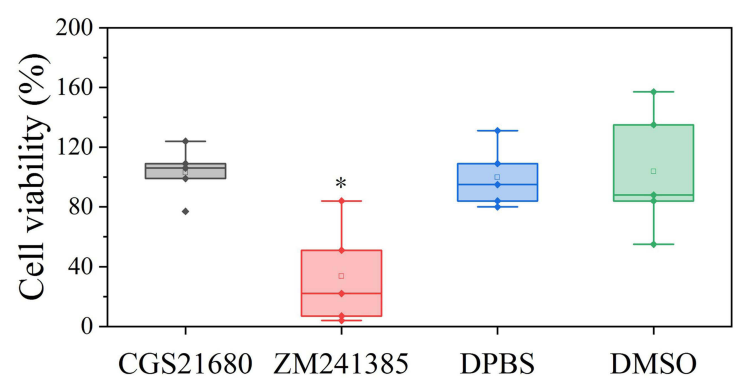

B

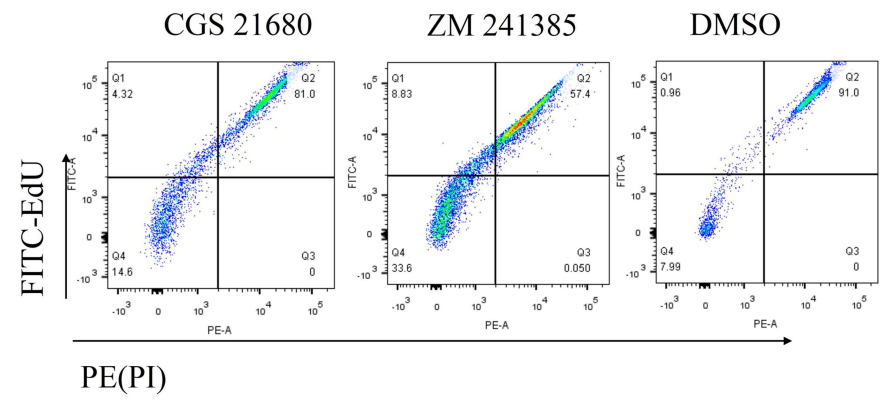

D

CGS 21680

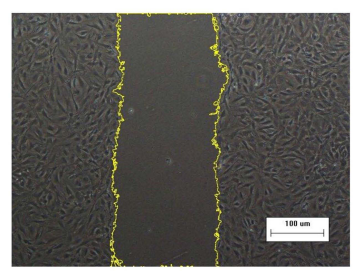

$0 \mathrm{~h}$

$24 \mathrm{~h}$
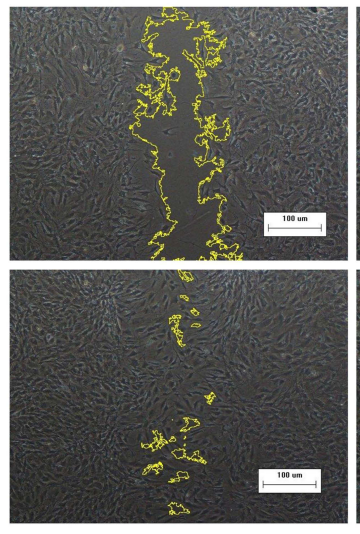

ZM 241385
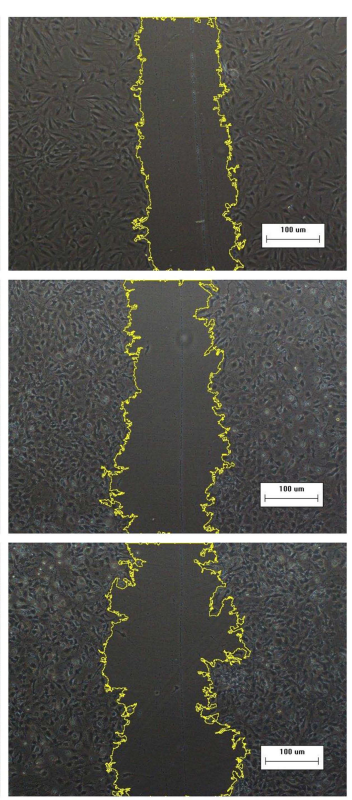

C
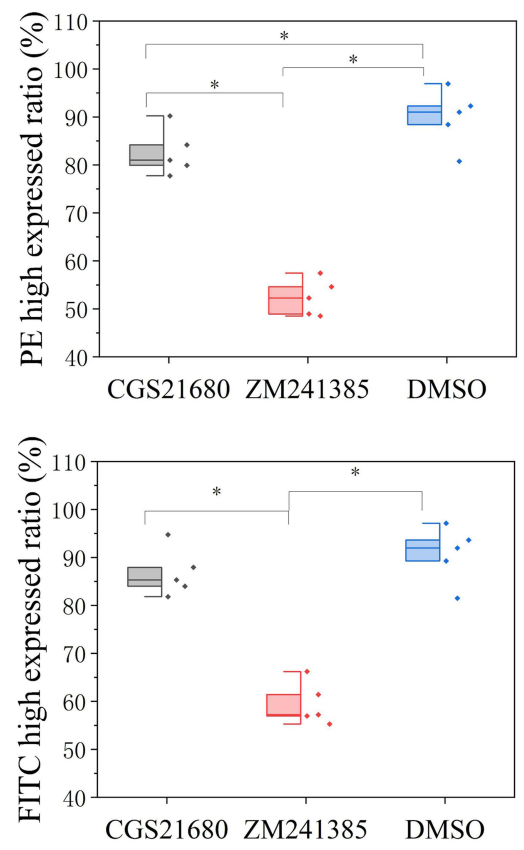

E
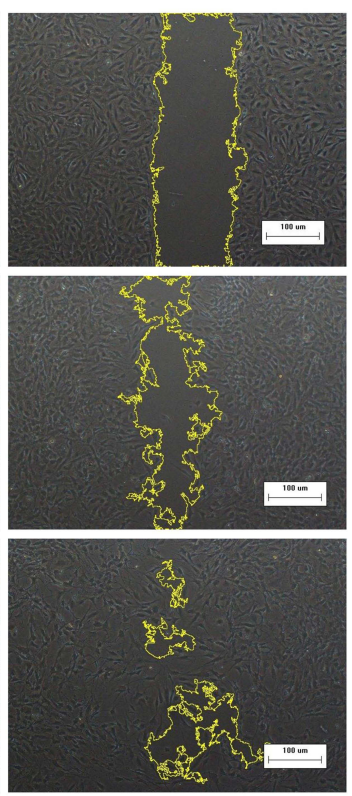

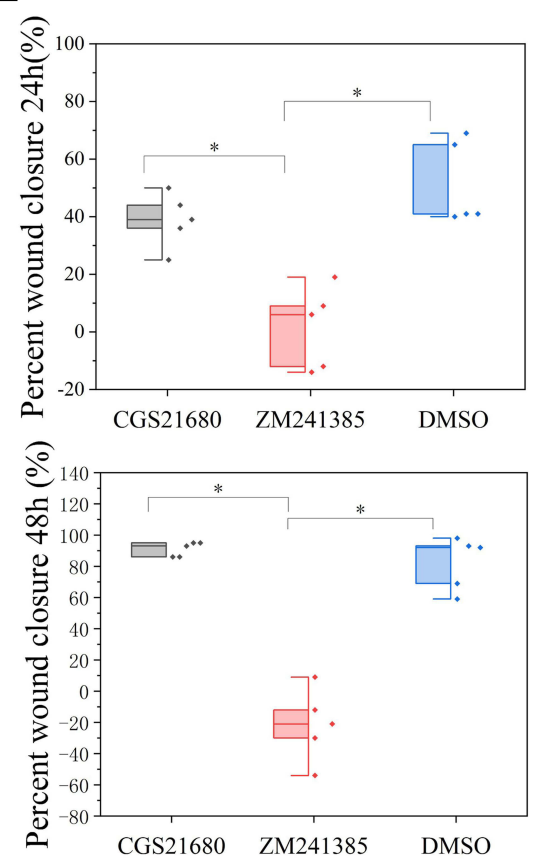

Figure 4 The role of ADA2AR on VECs viability and proliferation. (A) The box plots showed the CCK-8 assay results. ZM24I385 suppressed the VECs viability but CGS2 1680 could not enhance cell viability in bone fracture environment in vitro. * $p<0.05$ compared with DMSO treatment. $n=5$ for each group. (B) The results of EdU and $\mathrm{Pl}$ assay. CGS21680 could not enhance the FITC and PE expression in cells while ZM decreased the FITC and PE expression. (C) Half-box graphs analyzed the results of EdU and $\mathrm{Pl}$ assay, ${ }^{*}<0.05$. (D) Cell scratch assay results. CGS2I 680 could not promote wound closure and ZM 241385 inhibited wound closure at 24, 48h. Images $\times 40$; original scale bar, $100 \mu \mathrm{m}$. (E) Half-box graphs showed the difference between groups, ${ }^{*} \mathrm{p}<0.05 . \mathrm{n}=5$ for each group.

wound closure compared with DMSO treatment at $24 \mathrm{~h}$ and $48 \mathrm{~h}(\mathrm{p}=0.173$ and $\mathrm{p}=0.527$, respectively) (Figure $4 \mathrm{E})$.

The results of vascular tube formation showed that ZM241385 treatment decreased the number of branch points and capillary length compared with CGS21680 and DMSO treatments, and that this difference was statistically significant $(\mathrm{p}<0.05)$ (Figure 5B and C). CGS21680 treatment did not increase the number of branch points and capillary length compared with DMSO treatment $(\mathrm{p}=0.075$ and $\mathrm{p}=0.344$, respectively). 
A

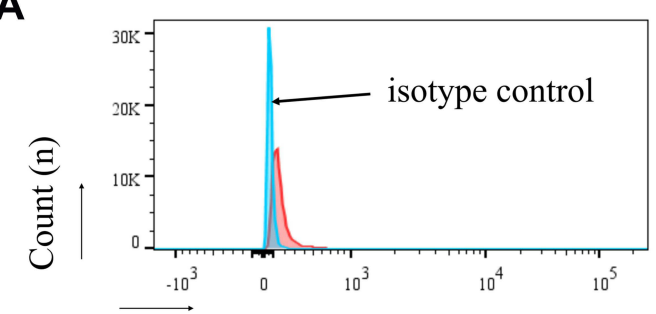

CD68 Alexa Fluor 488

B

$12 \mathrm{~h}$

Vascular branches

Cells marking

Calcein-AM

Staining
CGS 21680

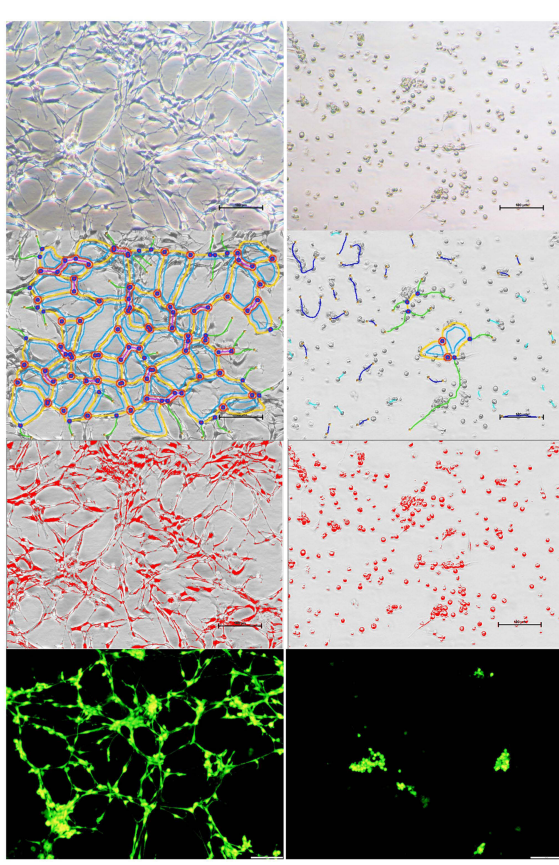

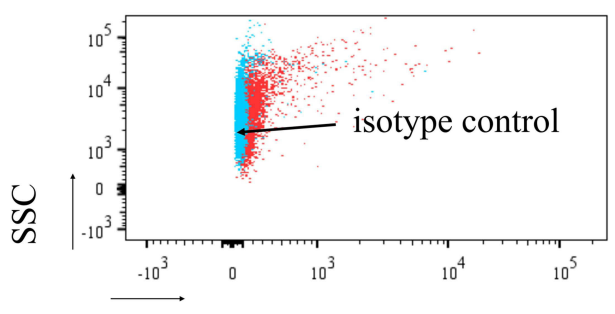

CD68 Alexa Fluor 488

C
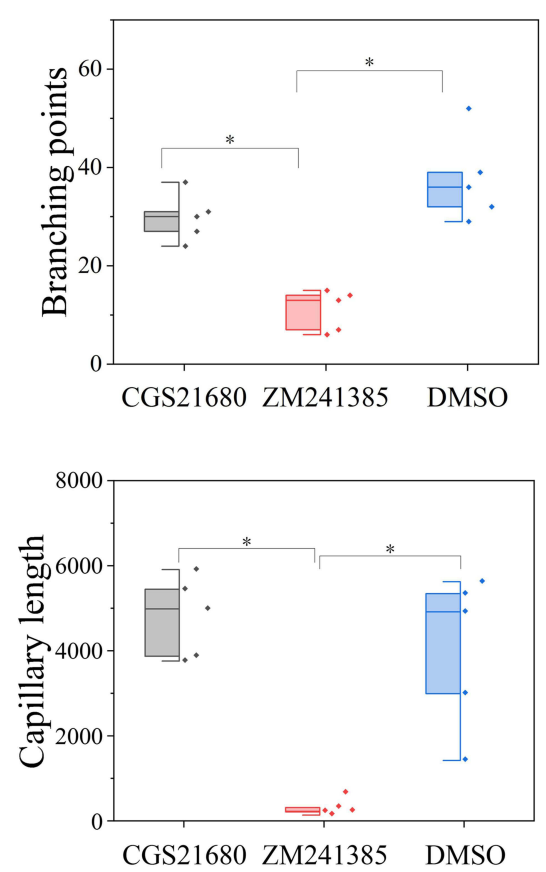

Figure 5 The role of ADA2AR on tube formation in vitro. (A) Rabbit anti-CD68/Alexa Fluor 488 antibody was used to identify the macrophages and rabbit lgG/Alexa Fluor 488 was the isotype control. (B) Vascular tube formation results. CGS 21680 could not promote tube formation and ZM24I385 inhibited tube formation at I2h. The contrast and brightness were evenly adjusted for each picture. Images $\times 100$; original scale bar, nonfluorescent images $100 \mu \mathrm{m}$; fluorescent images $50 \mu \mathrm{m}$. (C) Half-box graphs showed the difference between groups, ${ }^{*} \mathrm{p}<0.05$. $\mathrm{n}=5$ for each group.

\section{Effect of the ADA2AR on the Macrophage Regulation of VECs in vitro}

CGS21680 treatment and ZM241385 treatment increased the number of migrated cells compared with DMSO treatment and CGS21680+GW4869 treatment; these differences were statistically significant $(\mathrm{p}<0.05)$ (Figure 6A and B). However, there was no statistically significant difference in the number of migrated cells between CGS21680 and ZM241385 treatments $(p=0.463)$.

ZM241385 decreased the number of branch points and capillary length compared with CGS21680 treatment, CGS21680+GW4869 treatment, and DMSO treatment; for all comparisons, the difference was statistically significant $(p<0.05)$ (Figure 6C and D). However, CGS21680 treatment did not increase the number of branch points or capillary length compared with DMSO treatment $(\mathrm{p}=0.892$ and $\mathrm{p}=0.579$, respectively) (Figure 6C and D). The CGS21680 + GW4869 treatment decreased the number of branch points and capillary length compared with CGS21680 treatment, and these differences were statistically significant $(\mathrm{p}<0.05)$.

\section{Effect of the ADA2AR on Macrophages Exosomes Regulation of VECs in vitro}

CGS21680 accelerated exosome secretion by macrophages compared with ZM241385 treatment and DMSO treatment (Figure 7C). GW4869 reversed the effects of CGS21680 on the induction of exosome secretion by macrophages (Figure 7C).

GW4869 inhibited exosome secretion by macrophages and reversed the effects of CGS21680 on the macrophage 
A

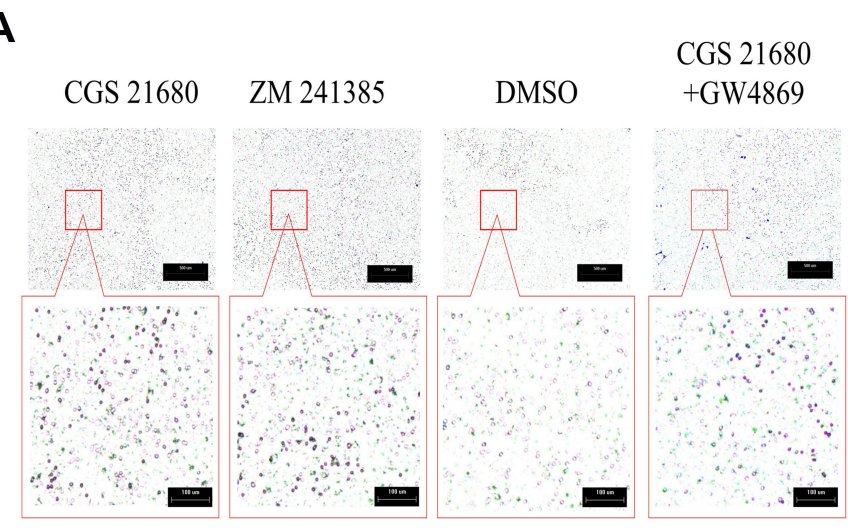

C
B

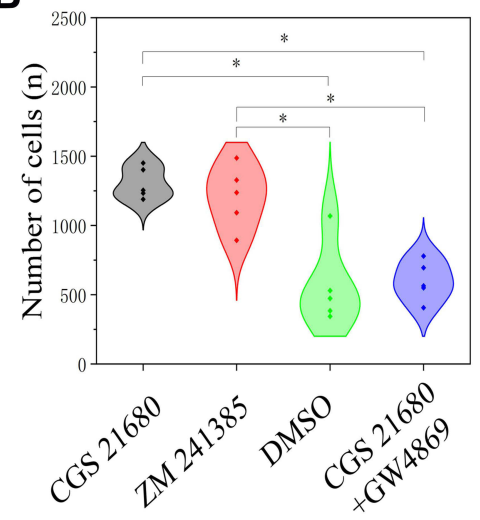

CGS 21680

+GW4869

D

$12 \mathrm{~h}$
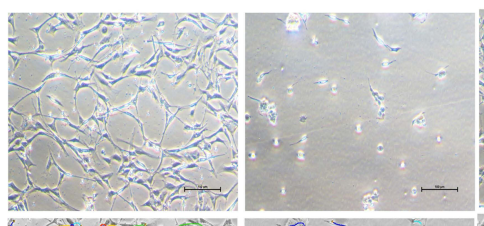

Vascular branches
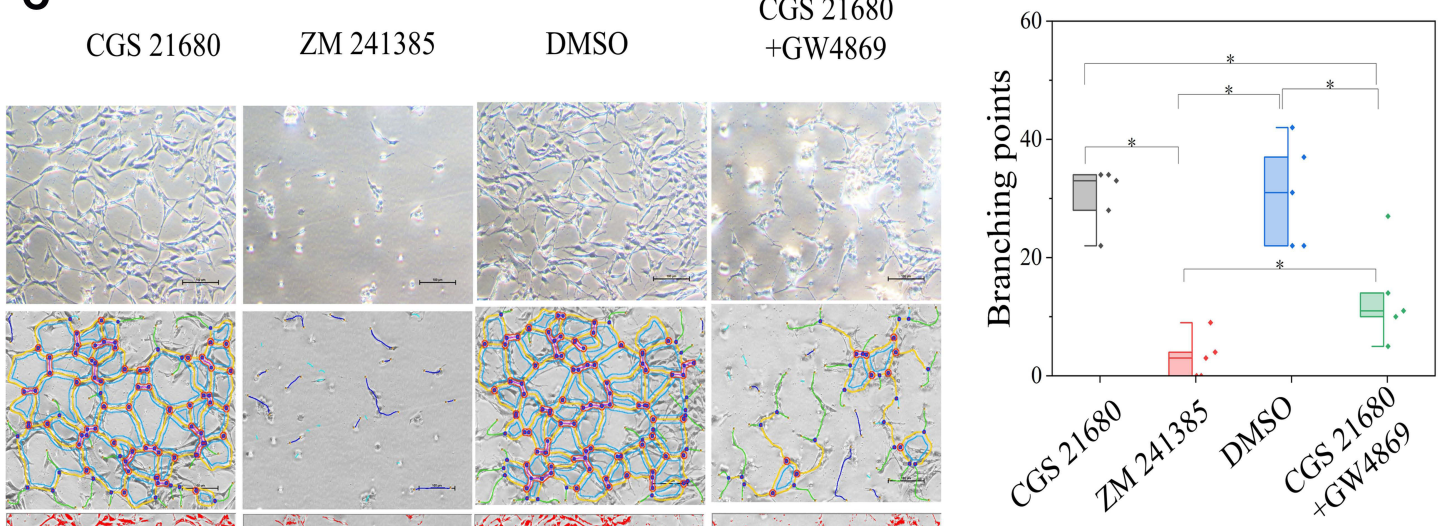

Cells marking
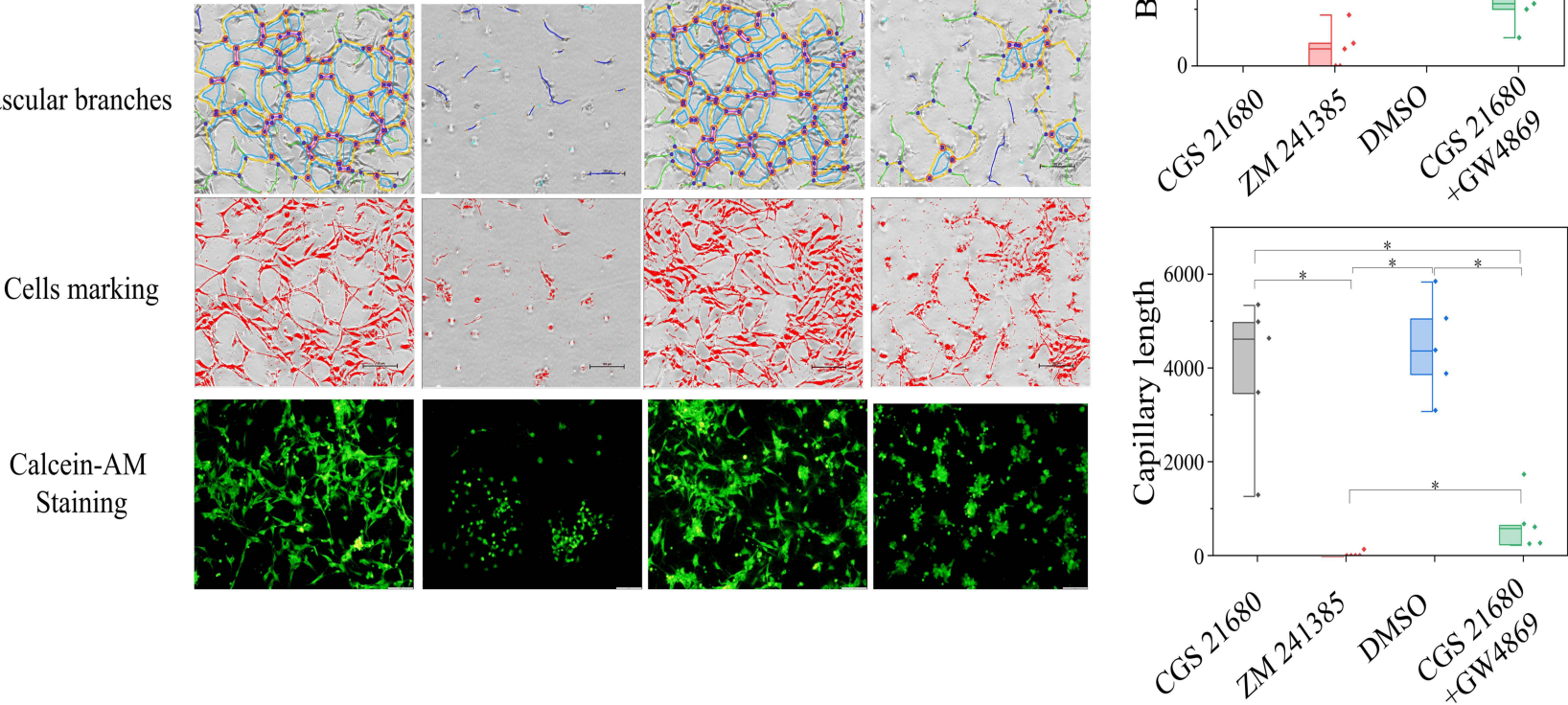

Figure 6 The role of ADA2AR in macrophages regulating VECs in BFM. (A) ADA2AR activation or inhibition had no difference on VECs migration in macrophage-VEC coculture model. Inhibited macrophage-exosomes weakened the VECs migration. Transwell images, $\times 50$; original scale bar, $100 \mu$ m. (B) Violin plots showed the cell migration results, ${ }^{*}<<0.05$. $n=5$. (C) Inhibited ADA2AR inhibited tube formation while activated ADA2AR had no significantly promote tube formation. Inhibited macrophage-exosomes inhibited the tube formation. The contrast and brightness were evenly adjusted for each picture. Images $\times 100$; original scale bar, nonfluorescent images $100 \mu \mathrm{m}$; fluorescent images $50 \mu \mathrm{m}$. (D) Half-box graphs showed the vascular tube formation results, * $\mathrm{p}<0.05$. $\mathrm{n}=5$.

regulation of VECs migration $(\mathrm{p}<0.05)$ (Figures $7 \mathrm{C}$ and $8 \mathrm{~A})$. However, the inhibition of exosome secretion by macrophages reversed the macrophage regulation of tube formation in VECs $(\mathrm{p}<0.05)$ (Figure $8 \mathrm{~B}$ and $\mathrm{C}$ ), suggesting that tube formation in VECs appeared to be more closely associated with exosome secretion by macrophages than the activation of the ADA2AR. The results showed that macrophages increased tube formation in VECs, likely in an ADA2AR-independent manner, but through a vesiclebased mechanism. 
A

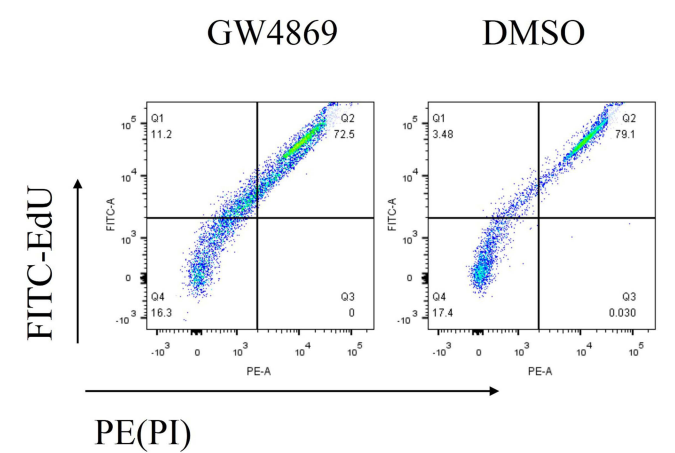

B

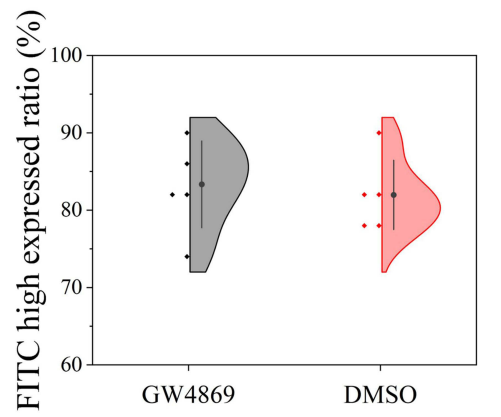

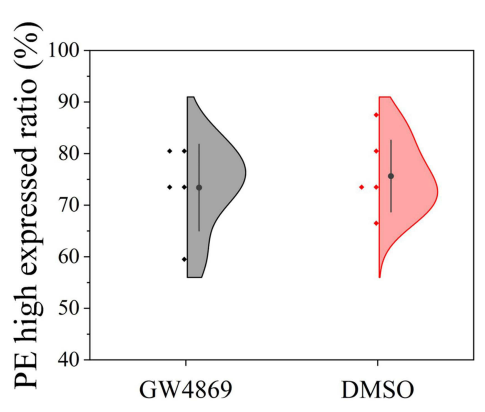

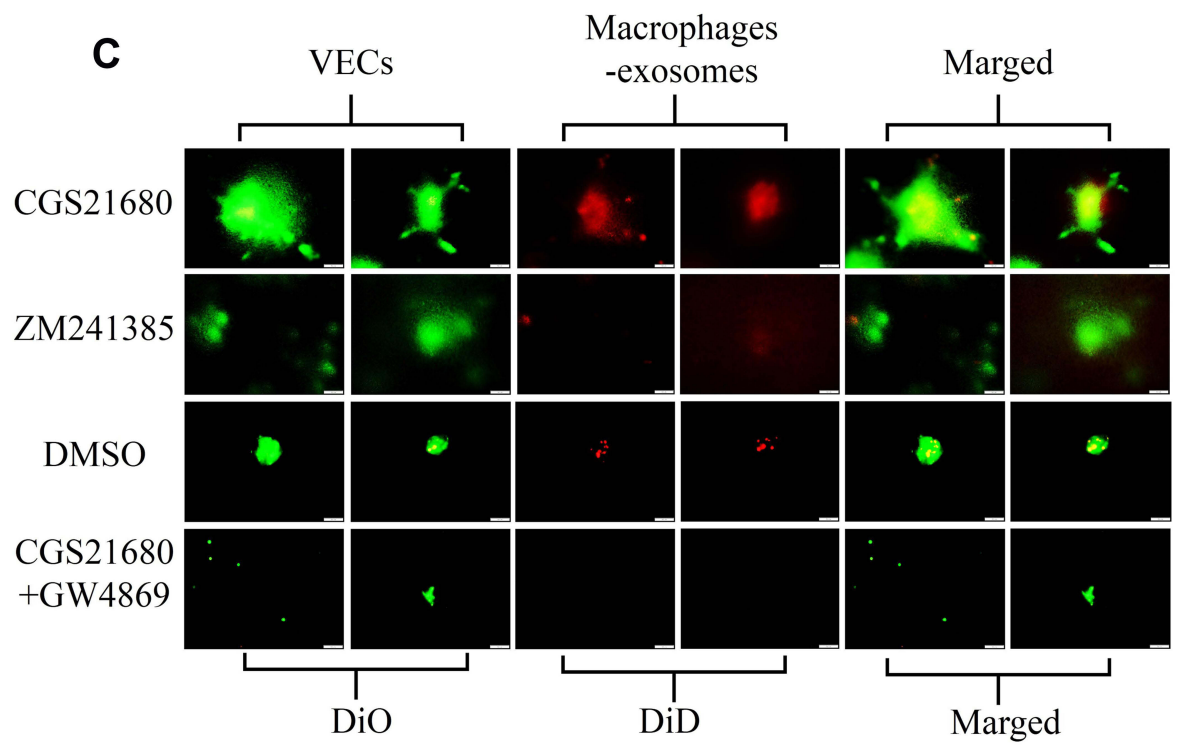

Figure 7 The role of ADA2AR in macrophages secreting exosomes in BFM. (A) GW4869 had no obvious cytotoxicity. The cell-light EdU Apollo 488 in vitro flow cytometry Kit and PI was used to evaluate the cytotoxicity. GW4869 did not significant decrease the FITC high expressed cells and increase the PE high expressed cells. (B) Half violin graph showed no statistic difference between the two groups, n=5. (C) CGS2I680 promoted macrophages secreting exosomes while ZM24I385 inhibited. DiD (red cell membrane markers) was used to mark macrophages and DiO (green cell membrane markers) used to mark VECs. $n=5$. The contrast and brightness were evenly adjusted for each picture. Images $\times 400$; original scale bar, $50 \mu \mathrm{m}$.

\section{Evaluation of the IncRNAs and mRNAs Involved in the Regulatory Effect of ADA2AR on VECs}

CGS21680 upregulated 3274 mRNAs and downregulated

2236 mRNAs (Supplementary Material) and upregulated 1696 lncRNAs and downregulated 1882 lncRNAs (Supplementary Material).

The GO analysis of differentially expression mRNAs showed that $369 \mathrm{GO}$ terms in the biological process category were enriched, 99 terms in the cellular component category were enriched, and 122 terms in the molecular function category were enriched. Moreover, 63 KEGG pathways were enriched, encompassing 61 genes related to the regulation of cell proliferation, 58 genes related to the positive regulation of cell migration, 56 genes relate to cell migration, and 275 genes related to metabolic pathways.

GSEA analysis of the mRNAs showed that the enrichment score was 0.75 for the apoptotic signaling pathway, 0.75 for the regulation of cellular response to stress, and 0.95 for the response to IL-6. The STRING 11.0 database was used to construct the PPI and the hub genes involved in the regulation of cell migration were Thbs1, Erbb4, and Flt1, which were downregulated, and Ntf3, Mmp3, Hras, and Pdgfrb, which were upregulated. The hub genes involved in metabolic pathways were Acox1, Cyp2e1, and Uqcrfs 1, which were downregulated, and Ugtlal and Pld1, which were upregulated.

The target genes of the differentially expressed lncRNAs were investigated and 7914 genes were determined as target 

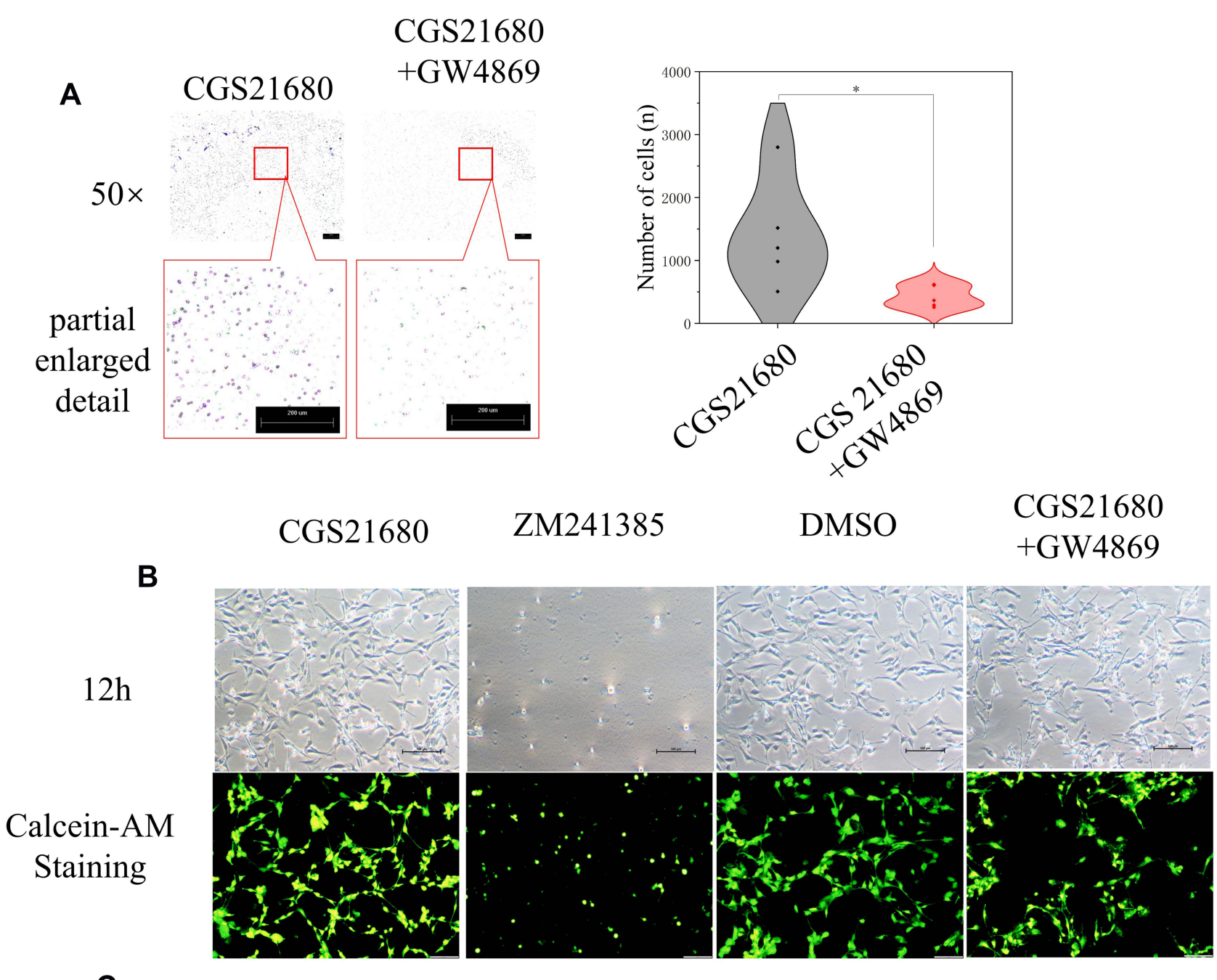

C
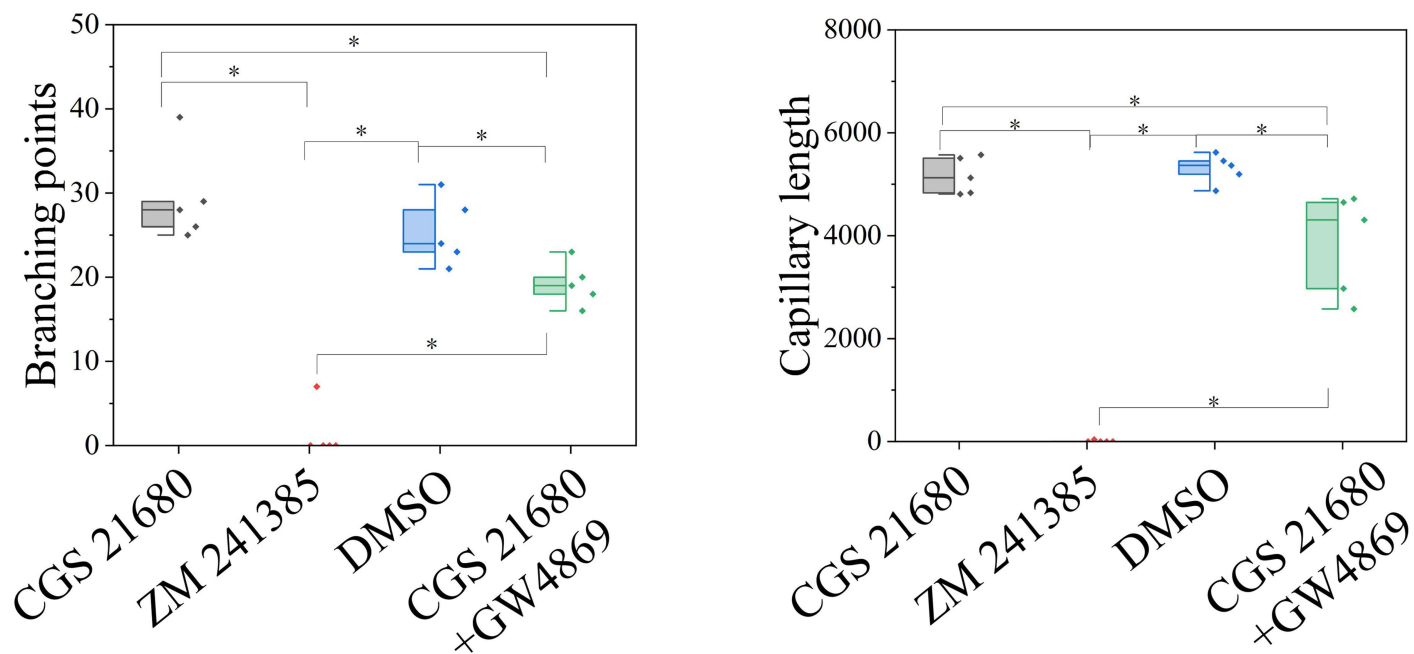

Figure 8 The role of ADA2AR in macrophage-exosomes regulating VECs. (A) inhibited macrophage secreting exosomes decreased the VECs migration. Macrophages were

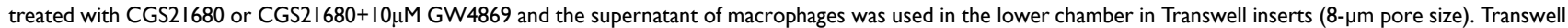
images, $\times 50$; original scale bar, $200 \mu \mathrm{m}$. The violin plots showed the difference between groups, ${ }^{*} \mathrm{p}<0.05$. $n=5$. (B) Inhibited macrophages-exosomes inhibited tube formation. Macrophages were treated with CGS21680, ZM241385, DMSO or CGS2I680+GW4869 and the supernatant of macrophages was used. The contrast and brightness were evenly adjusted for each picture. Images $\times 100$; original scale bar, nonfluorescent images $100 \mu \mathrm{m}$; fluorescent images $50 \mu \mathrm{m}$. (C) Half-box graphs showed the difference between groups, ${ }^{*} \mathrm{p}<0.05 . \mathrm{n}=5$. 
genes by the co-location method (Supplementary Material). In the GO analysis, 269 terms in the biological process category were enriched, 89 terms in the cellular component category were enriched, and 112 terms in the molecular function were enriched. Moreover, in the KEGG analysis, 66 pathways terms were enriched; 60 genes were associated with vesicle-mediated transport, 77 genes were associated with angiogenesis, and 53 genes were associated with the cell cycle. The hub genes involved in angiogenesis were Flt1, Fgf2, Mapk14, Fn1, and Jun. The hub genes involved in vesicle-mediated transport were Vamp2, Vamp7, Vamp8, Cltc, and Bnipl (Figure 9).

\section{Discussion}

Our studies were the first to examine the role of the ADA2AR in angiogenesis during bone healing. CGS21680 was used to activate the ADA2AR and ZM241385 was used to inactivate the receptor. First, we verified that CGS21680 promoted new bone formation and callus formation, and that ZM241385 inhibited new bone formation and callus formation by Goldner trichrome staining. In 2020, we proposed that CGS21680 promoted bone healing and ZM241385 inhibited bone healing in a rat tibial fracture model, ${ }^{2}$ as previous studies found that CGS21680 accelerated bone regeneration in a mouse model of skull bone defects. ${ }^{2,17-19}$ However, we used a gelatin sponge and administered the drug every $24 \mathrm{~h}$ in this study, a different method from the previous study, in which a fibrin gel drug delivery system was used and the rats did not receive the drugs after the model was established. ${ }^{2}$

There has been no previous investigation of the effect of the ADA2AR on angiogenesis during bone healing. We used CD31 immunofluorescence and vWF immunohistochemical staining to evaluate the effect of the ADA2AR on angiogenesis during bone healing. The immunofluorescence and immunohistochemical analyses showed that CGS21680 promoted angiogenesis during bone healing and ZM241385 inhibited angiogenesis in the early stage of bone healing. Angiogenesis is essential for bone healing. ${ }^{39}$ If angiogenesis does not occur in the early stage of fracture healing bone nonunion will occur, even if vascularization occurs in the late stage of fracture healing.

In this study, we used a model of periosteum damage, as it is described in the previous studies to cause bone nonunion in rats. ${ }^{2,24}$ We found that the activation of the ADA2AR was essential for angiogenesis in the early stage of bone healing. ZM241385 suppressed angiogenesis and caused excessive inflammatory responses. However, it was not determined if this was due to drug toxicity or receptor antagonism and this remains an important question for future studies. The activation of the ADA2AR by CGS21680 promoted angiogenesis. The serum from rats with a tibial fracture was used to simulate the fracture microenvironment for an investigation of the regulatory mechanism of the ADA2AR on VECs in bone healing. Unexpectedly, we found that no dose of CGS2680 tested (from $100 \mathrm{ng} / \mu \mathrm{L}$ to $0.05 \mathrm{ng} / \mu \mathrm{L}$ ) increased VEC proliferation, as shown by the CCK-8 test. Moreover, ZM241385 significantly suppressed cell proliferation, which was similar to the in vivo results. The scratch assay and vascular tube formation assay were performed to verify the results of CCK-8 tests and similar results were obtained. EdU/PI staining also confirmed the CCK- 8 results. CGS21680 did not enhance VEC proliferation and ZM241385 inhibited VEC proliferation. We found that ZM241385 resulted in fewer PI-expressing cells but more nonadherent cells, which we believed confirmed that there was no significant change in the cell membrane integrity of VECs. The reason for the significant decrease in adherent cells and decreased cell activity may be attributable to the increased cell permeability caused by programmed cell death. This result needs to be confirmed in future studies.

The migration of VECs is important for angiogenesis, but CGS21680 did not promote VEC migration in vitro. This contrasted with the in vivo results, so we hypothesized that there may be a lack of key regulatory cells in the in vitro environment. Macrophages are one of the most important activators of VECs in the early stages of bone healing, so we used a cell co-culture model to explore the effects of the ADA2AR on VECs. ${ }^{10-12}$ We found that CGS21680 enhanced VEC migration and ZM241385 inhibited vessel formation in the cell co-culture model. We thought that the effects of CGS21680 on macrophageVECs were related to exosomes, therefore we used GW4869 to inhibit exosome secretion. ${ }^{40}$ Both the inhibition and activation of the ADA2AR had a similar effect on VEC migration in cell co-culture, showing that the induction of the VEC migration by macrophages was not attributable to the ADA2AR. The effect appears to be more closely associated with the release of vesicles by macrophages than the activation of the ADA2AR. Furthermore, we analyzed the supernatant of the stimulated macrophages. We found that the inhibition of exosome secretion by macrophages could significantly weaken tube formation. These results suggested that exosome secretion from macrophages was important for the effect of the ADA2AR 
A

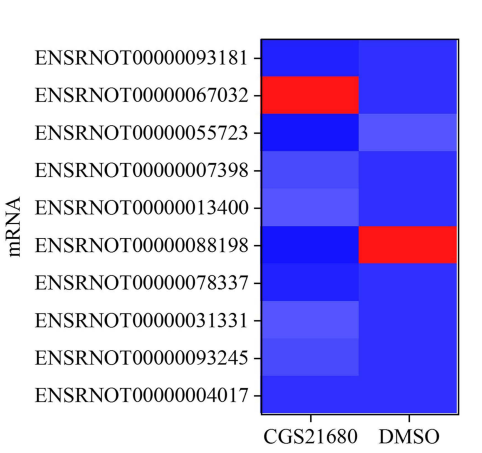

B

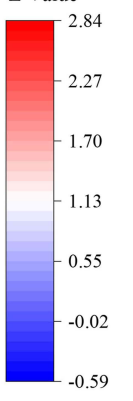

TCONS_00131706 TCONS_00000364 TCONS_00053228 TCONS_00133612 TCONS_00006728 巳 TCONS_00057435 ENSRNOT00000093096 TCONS_00006720 TCONS_00000379 TCONS_00000378

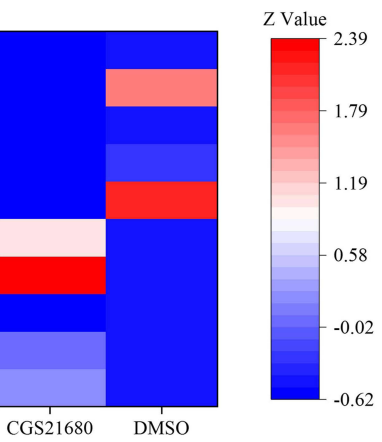

C

PI3K-Akt signaling pathway

Ras signaling pathway

MAPK signaling pathway

cAMP signaling pathway

Metabolic pathways -

response to cAMP cell migration

bone mineralization osteoblast differentiation wound healing -

inflammatory response
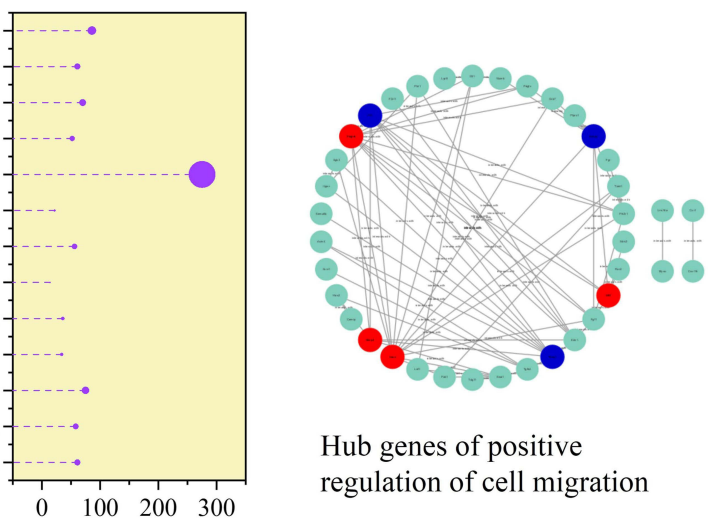

Hub genes of positive regulation of cell migration

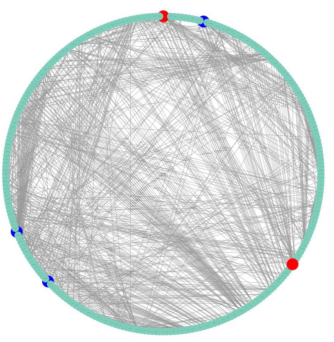

positive regulation of cell migration regulation of cell proliferation

mRNAs numbers(n)

D

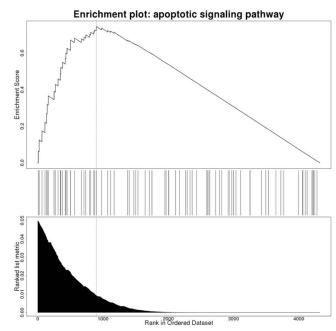

apoptotic signaling pathway EnrichmentScore:0.75 P-value:0.06

FDR:1

E

$$
\text { Size:83 }
$$

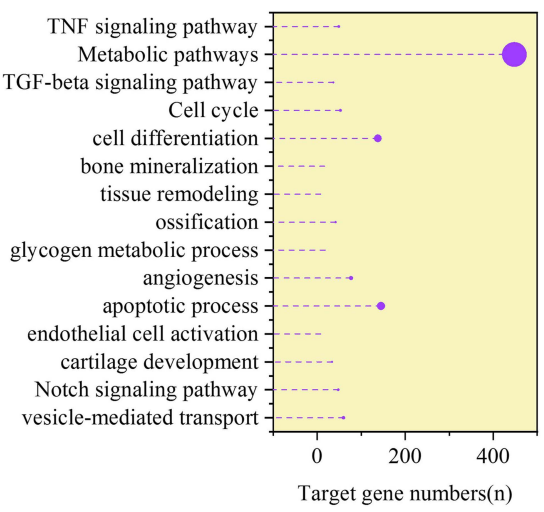

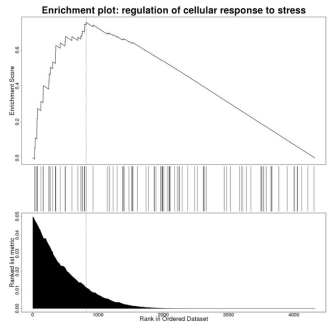

regulation of cellular response to stress EnrichmentScore:0.75

P-value:0.01

FDR:1

Size:96

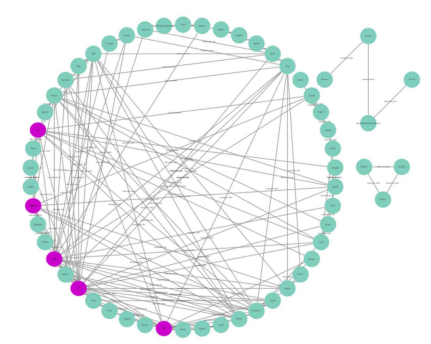

Hub genes of angiogenesis
Hub genes of metabolic pathways

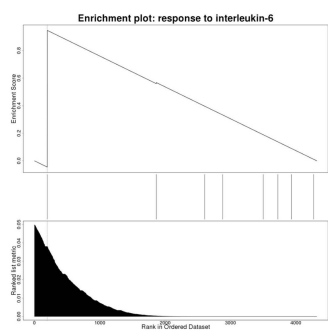

response to interleukin-6

EnrichmentScore:0.95

P-value:0.02

FDR:1

Size:8

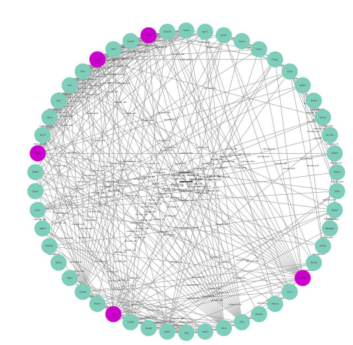

Hub genes of vesicle-mediated transport

Figure 9 The involved IncRNAs and mRNAs in the regulatory of ADA2AR on VECs. (A and B) The top 10 different expressed mRNAs and IncRNAs. (C) The GO and KEGG analysis of different expressed mRNAs, in addition, the hub genes in ADA2AR on cell migration and metabolic pathways (red: upregulated red, blue: downregulated). The results were based on the different expressed mRNAs. (D) GSEA analysis of different expressed mRNAs. (E) The GO and KEGG analysis of the target genes of different expressed IncRNAs, in addition, the hub genes in ADA2AR on angiogenesis and vesicle-mediated transport (purple). 
on angiogenesis during bone healing and that the inactivation of ADA2AR would suppress angiogenesis.

We analyzed the mechanism of the activated ADA2AR on VECs during bone healing from a genetic perspective. We found that CGS21680 upregulated 3274 mRNAs and downregulated 2236 mRNAs, and upregulated 1696 lncRNAs and downregulated 1882 lncRNAs. Moreover, the most affected pathway was metabolism, with the expression of 275 mRNAs altered. The hub genes in the metabolic pathways were Ugt1a1, Pld1, Uqcrfs1, Cyp2e1, and Acox1. A few studies have discussed the involvement of the above genes in VEC metabolism. ${ }^{41,42}$ Zhang et $\mathrm{al}^{41}$ proposed that Pld1-dependent PKC $\gamma$ activation was essential for the development of pathologic retinal neovascularization. Chakkalakal et $\mathrm{al}^{42}$ analyzed Cyp2el in metabolic pathways in the liver during bone healing. However, they analyzed Cyp2e1 to evaluate the influence of excessive alcohol consumption on the liver in the process of fracture healing, and the influence of Cyp2el on fracture healing and bone metabolism has not been discussed. ${ }^{42}$ Unfortunately, no studies have explored the effect of Ugtla1, Pld1, Uqcrfs1, Cyp2e1, and Acox1 in bone metabolic pathways during bone healing.

From the bioinformatic analysis, we found that $F n 1$, Mapk14, Jun, Flt1 and Fgf2 may be the key genes involved in the effect of the ADA2AR on angiogenesis during bone healing. $\mathrm{Ji}$ et $\mathrm{al}^{43}$ proposed that Flt1 was the key regulator of fetoplacental endothelial cell migration and angiogenesis. Nesmith et $\mathrm{al}^{44}$ found that blood vessel endothelial sprout anastomosis was regulated by Flt1 during angiogenesis. Gao et $\mathrm{al}^{45}$ proposed that microRNA613 exerted an anti-angiogenic effect on nasopharyngeal carcinoma cells through the inactivation of the Akt signaling pathway by downregulating Fnl. Although the above studies have the involvement of Fn1, Mapk14, Jun, Flt1, and $F g f 2$ in angiogenesis, the effect of these genes in angiogenesis during bone healing have not been studied.

Overall, the activation of the ADA2AR is essential for angiogenesis during bone healing. ADA2AR agonists may be the next potential pharmaceutic preparation for bone fracture when the local blood supply is disturbed.

\section{Conclusions}

We explored the effect of the activated ADA2AR on VECs and macrophages in the bone fracture environment in vivo and in vitro. We found that the inactivation of the ADA2AR suppressed VEC proliferation during bone healing. It also inhibited VEC migration, tube formation, and the macrophage regulation of VECs. In the in vivo experiments, the activated ADA2AR promoted VEC proliferation during bone healing, but did not increase VEC viability, migration, or tube formation in vitro. This may be attributable to the complex regulatory network present in vivo. CGS21680 promoted exosome secretion by macrophages. The hub genes involved in the activation of ADA2AR on angiogenesis were Flt1, Fgf2, Mapk14, Fn1, and Jun.

\section{Abbreviations}

ADA2AR, adenosine A2A receptor; VECs, vascular endothelial cells; lncRNAs, long non-coding RNAs; SD, Sprague-Dawley; EDTA, ethylene diamine tetraacetic acid; PBMC, peripheral blood mononuclear cell; DPBS, Dulbecco's phosphate buffered saline; FBS, fetal bovine serum; BFM, bone fracture environment medium; CCK-8, Cell Counting Kit-8; DMSO, dimethyl sulfoxide; ANOVA, Analysis of Variance; LSD, least significant difference; PI, propidium iodide; DAVID, Database for Annotation, Visualization and Integrated Discovery; KEGG, Kyoto Encyclopedia of Genes and Genomes; PPI, protein-protein interaction; GO, Gene Ontology; BP, Biological Process; CC, Cellular Component; MF, Molecular Function; GSEA, gene set enrichment analysis.

\section{Data Sharing Statement}

The supplemental data used to support the findings of this study have been submitted with the manuscript.

\section{Ethics Approval}

This article does not contain any studies with human participants performed by any of the authors. The present study was approved by the Capital Medical University Ethics Committee on the use of animals in research and education (approval no. AEEI-2020-088, AEEI-2020-103, AEEI-2021-120).

\section{Consent for Publication}

All authors agreed to the publication of this research.

\section{Acknowledgments}

We thank the medical research center of Beijing Chaoyang Hospital to provide the experimental place and the related software used in this research. We thank Procell Life Science\&Technology Co., Ltd provided the vascular endothelial cells and the medium, besides, Charles River Laboratories provided the rats. In addition, we thank Beijing Novogene Technology Co., Ltd to complete the 
high throughput sequencing and primarily analyze the mRNA and lncRNA results.

\section{Author Contributions}

All authors contributed to data analysis, drafting or revising the article, gave final approval of the version to be published, agreed to the submitted journal, and agree to be accountable for all aspects of the work.

\section{Funding}

This study was supported by the scientific research and cultivation fund of Capital Medical University (PYZ19021) and scientific cultivation fund of Beijing Chaoyang hospital (CYYPY201929).

\section{Disclosure}

The authors have no conflicts of interest or financial disclosures in this work.

\section{References}

1. Zura R, Xiong Z, Einhorn T, et al. Epidemiology of fracture nonunion in 18 human bones. JAMA Surg. 2016;151(11):e162775. doi:10.1001/ jamasurg.2016.2775

2. Zheng $\mathrm{X}$, Wang D. The adenosine a2a receptor agonist accelerates bone healing and adjusts Treg/Th17 cell balance through Interleukin 6. Biomed Res Int. 2020;2020:2603873.

3. Reahl GB, Gerstenfeld L, Kain M. Epidemiology, clinical assessments, and current treatments of nonunions. Curr Osteoporos Rep. 2020;18(3):157-168. doi:10.1007/s11914-020-00575-6

4. Ding ZC, Lin YK, Gan YK, Tang TT. Molecular pathogenesis of fracture nonunion. J Orthop Translat. 2018;14:45-56. doi:10.1016/j. jot.2018.05.002

5. Sturtzel C. Endothelial cells. Adv Exp Med Biol. 2017;1003:71-91.

6. Rohlenova K, Veys K, Miranda-Santos I, De Bock K, Carmeliet P. Endothelial cell metabolism in health and disease. Trends Cell Biol. 2018;28(3):224-236. doi:10.1016/j.tcb.2017.10.010

7. Ghiasi MS, Chen J, Vaziri A, Rodriguez EK, Nazarian A. Bone fracture healing in mechanobiological modeling: a review of principles and methods. Bone Rep. 2017;6:87-100. doi:10.1016/j. bonr.2017.03.002

8. Diomede F, Marconi GD, Fonticoli L, et al. Functional relationship between osteogenesis and angiogenesis in tissue regeneration. Int J Mol Sci. 2020;21(9):3242. doi:10.3390/ijms21093242

9. Peng L, Fu C, Wang L, et al. The effect of pulsed electromagnetic fields on angiogenesis. Bioelectromagnetics. 2021;42(3):250-258. doi: $10.1002 /$ bem. 22330

10. Sass FA, Fuchs M, Pumberger M, et al. Immunology guides skeletal muscle regeneration. Int J Mol Sci. 2018;19(3):835. doi:10.3390/ ijms 19030835

11. Guo S, Yu D, Xiao X, et al. A vessel subtype beneficial for osteogenesis enhanced by strontium-doped sodium titanate nanorods by modulating macrophage polarization. J Mater Chem B. 2020;8 (28):6048-6058. doi:10.1039/D0TB00282H

12. Sivaraj KK, Adams RH. Blood vessel formation and function in bone. Development. 2016;143(15):2706-2715. doi:10.1242/ dev. 136861
13. Guerrero A. A2A adenosine receptor agonists and their potential therapeutic applications. An update. Curr Med Chem. 2018;25 (30):3597-3612. doi:10.2174/0929867325666180313110254

14. Palmer TM, Trevethick MA. Suppression of inflammatory and immune responses by the $\mathrm{A}(2 \mathrm{~A})$ adenosine receptor: an introduction. $B r \quad J$ Pharmacol. 2008;153(Suppl 1):S27-S34. doi:10.1038/sj.bjp.0707524

15. Montesinos MC, Shaw JP, Yee H, Shamamian P, Cronstein BN. Adenosine $\mathrm{A}(2 \mathrm{~A})$ receptor activation promotes wound neovascularization by stimulating angiogenesis and vasculogenesis. Am J Pathol. 2004;164(6):1887-1892. doi:10.1016/S0002-9440(10)63749-2

16. Montesinos MC, Desai A, Chen JF, et al. Adenosine promotes wound healing and mediates angiogenesis in response to tissue injury via occupancy of $\mathrm{A}(2 \mathrm{~A})$ receptors. Am $J$ Pathol. 2002;160 (6):2009-2018. doi:10.1016/S0002-9440(10)61151-0

17. Mediero A, Wilder T, Perez-Aso M, Cronstein BN. Direct or indirect stimulation of adenosine A2A receptors enhances bone regeneration as well as bone morphogenetic protein-2. FASEB J. 2015;29 (4):1577-1590. doi:10.1096/fj.14-265066

18. Mediero A, Wilder T, Shah L, Cronstein BN. Adenosine A2A receptor (A2AR) stimulation modulates expression of semaphorins $4 \mathrm{D}$ and 3A, regulators of bone homeostasis. FASEB J. 2018;32 (7):3487-3501. doi:10.1096/fj.201700217R

19. Lopez CD, Bekisz JM, Corciulo C, et al. Local delivery of adenosine receptor agonists to promote bone regeneration and defect healing. Adv Drug Deliv Rev. 2019;146:240-247. doi:10.1016/j. addr.2018.06.010

20. Desai A, Victor-Vega C, Gadangi S, Montesinos MC, Chu CC, Cronstein $\mathrm{BN}$. Adenosine A2A receptor stimulation increases angiogenesis by down-regulating production of the antiangiogenic matrix protein thrombospondin 1. Mol Pharmacol. 2005;67(5):1406-1413. doi:10.1124/mol.104.007807

21. Dubey RK, Gillespie DG, Jackson EK. A(2B) adenosine receptors stimulate growth of porcine and rat arterial endothelial cells. Hypertension. 2002;39(2 Pt 2):530-535. doi:10.1161/hy0202.103075

22. Grant MB, Tarnuzzer RW, Caballero S, et al. Adenosine receptor activation induces vascular endothelial growth factor in human retinal endothelial cells. Circ Res. 1999;85(8):699-706. doi:10.1161/01. RES.85.8.699

23. Bonyanian Z, Walker M, Du Toit E, Rose'Meyer RB. Multiple adenosine receptor subtypes stimulate wound healing in human EA. hy926 endothelial cells. Purinergic Signal. 2019;15(3):357-366. doi:10.1007/s11302-019-09668-z

24. Ernens I, Bousquenaud M, Lenoir B, Devaux Y, Wagner DR. Adenosine stimulates angiogenesis by up-regulating production of thrombospondin-1 by macrophages. J Leukoc Biol. 2015;97 (1):9-18. doi:10.1189/jlb.3HI0514-249RR

25. Du X, Ou X, Song T, et al. Adenosine A2B receptor stimulates angiogenesis by inducing VEGF and eNOS in human microvascular endothelial cells. Exp Biol Med (Maywood). 2015;240 (11):1472-1479. doi:10.1177/1535370215584939

26. Wu XQ, Wang D, Liu Y, Zhou JL. Development of a tibial experimental non-union model in rats. J Orthop Surg Res. 2021;16(1):261. doi:10.1186/s13018-021-02408-3

27. Saeed A, Abolaban F. Risk estimation of the low-dose fast neutrons on the molecular structure of the lipids of peripheral blood mononuclear cells. Biochem Biophys Res Commun. 2020;533 (4):1048-1053. doi:10.1016/j.bbrc.2020.09.116

28. Xie W, Zhou X, Hu W, et al. Pterostilbene accelerates wound healing by modulating diabetes-induced estrogen receptor beta suppression in hematopoietic stem cells. Burns Trauma. 2021;9:tkaa045. doi:10.1093/burnst/tkaa045

29. Liu S, Li W, Xu M, Huang H, Wang J, Chen X. Micro-RNA 21Targets dual specific phosphatase 8 to promote collagen synthesis in high glucose-treated primary cardiac fibroblasts. Can J Cardiol. 2014;30(12):1689-1699. doi:10.1016/j.cjca.2014.07.747 
30. Schneider CA, Rasband WS, Eliceiri KW. NIH image to imageJ: 25 years of image analysis. Nat Methods. 2012;9(7):671-675. doi:10.1038/nmeth.2089

31. Xu D, Liu T, He L, Han D, Ma Y, Du J. LncRNA MEG3 inhibits HMEC-1 cells growth, migration and tube formation via sponging miR-147. Biol Chem. 2020;401(5):601-615. doi:10.1515/hsz-20190230

32. Wang D, Liu Y, Yang X, Zhou J. Hypoxic preconditioning enhances cell hypoxia tolerance and correlated lncRNA and mRNA analysis. Life Sci. 2018;208:46-54. doi:10.1016/j.1fs.2018.07.014

33. Huang da W, Sherman BT, Lempicki RA. Systematic and integrative analysis of large gene lists using DAVID bioinformatics resources. Nat Protoc. 2009;4(1):44-57. doi:10.1038/nprot.2008.211

34. Huang da W, Sherman BT, Lempicki RA. Bioinformatics enrichment tools: paths toward the comprehensive functional analysis of large gene lists. Nucleic Acids Res. 2009;37(1):1-13. doi:10.1093/nar/ gkn923

35. Wang J, Vasaikar S, Shi Z, Greer M, Zhang B. WebGestalt 2017: a more comprehensive, powerful, flexible and interactive gene set enrichment analysis toolkit. Nucleic Acids Res. 2017;45(W1):W130 W137. doi:10.1093/nar/gkx356

36. Szklarczyk D, Gable AL, Lyon D, et al. STRING v11: protein-protein association networks with increased coverage, supporting functional discovery in genome-wide experimental datasets. Nucleic Acids Res. 2019;47(D1):D607-D613. doi:10.1093/nar/gky1131

37. Shannon P, Markiel A, Ozier O, et al. Cytoscape: a software environment for integrated models of biomolecular interaction networks. Genome Res. 2003;13(11):2498-2504. doi:10.1101/gr.1239303
38. Otasek D, Morris JH, Boucas J, Pico AR, Demchak B. Cytoscape automation: empowering workflow-based network analysis. Genome Biol. 2019;20(1):185. doi:10.1186/s13059-019-1758-4

39. Filipowska J, Tomaszewski KA, Niedzwiedzki L, Walocha JA, Niedzwiedzki T. The role of vasculature in bone development, regeneration and proper systemic functioning. Angiogenesis. 2017;20 (3):291-302. doi:10.1007/s10456-017-9541-1

40. Baer C, Squadrito ML, Iruela-Arispe ML, De Palma M. Reciprocal interactions between endothelial cells and macrophages in angiogenic vascular niches. Exp Cell Res. 2013;319(11):1626-1634. doi:10.1016/j.yexcr.2013.03.026

41. Zhang Q, Wang D, Kundumani-Sridharan V, et al. PLD1-dependent PKCgamma activation downstream to src is essential for the development of pathologic retinal neovascularization. Blood. 2010;116 (8):1377-1385. doi:10.1182/blood-2010-02-271478

42. Chakkalakal DA, Novak JR, Fritz ED, et al. Inhibition of bone repair in a rat model for chronic and excessive alcohol consumption. Alcohol. 2005;36(3):201-214. doi:10.1016/j.alcohol.2005.08.001

43. Ji S, Xin H, Li Y, Su EJ. FMS-like tyrosine kinase 1 (FLT1) is a key regulator of fetoplacental endothelial cell migration and angiogenesis. Placenta. 2018;70:7-14. doi:10.1016/j.placenta.2018.08.004

44. Nesmith JE, Chappell JC, Cluceru JG, Bautch VL. Blood vessel anastomosis is spatially regulated by Flt1 during angiogenesis. Development. 2017;144(5):889-896. doi:10.1242/dev.145672

45. Gao R, Feng Q, Tan G. microRNA-613 exerts anti-angiogenic effect on nasopharyngeal carcinoma cells through inactivating the AKT signaling pathway by down-regulating FN1. Biosci Rep. 2019;39(7). doi:10.1042/BSR20182196
Journal of Inflammation Research

\section{Publish your work in this journal}

The Journal of Inflammation Research is an international, peerreviewed open-access journal that welcomes laboratory and clinical findings on the molecular basis, cell biology and pharmacology of inflammation including original research, reviews, symposium reports, hypothesis formation and commentaries on: acute/chronic inflammation; mediators of inflammation; cellular processes; molecular mechanisms; pharmacology and novel anti-inflammatory drugs; clinical conditions involving inflammation. The manuscript management system is completely online and includes a very quick and fair peerreview system. Visit http://www.dovepress.com/testimonials.php to read real quotes from published authors.

Submit your manuscript here: https://www.dovepress.com/journal-of-inflammation-research-journal 